\title{
Xanthine, xanthosine and its nucleotides: solution structures of neutral and ionic forms, and relevance to substrate proper- ties in various enzyme systems and metabolic pathways ${ }^{*}$
}

\author{
Ewa Kulikowska ${ }^{1}$, Borys Kierdaszuk ${ }^{1}$ and David Shugar ${ }^{1,2}$ \\ ${ }^{1}$ Department of Biophysics, Institute of Experimental Physics, University of Warsaw, 93 Zwirki \\ $i$ Wigury, 02-089 Warszawa, and ${ }^{2}$ Institute of Biochemistry and Biophysics, Polish Academy \\ of Sciences, 5a A. Pawinskiego, 02-106 Warszawa, Poland
}

Received: 09 May, 2004

Key words: xanthine, xanthosine, nucleotides, acid/base properties, prototropic tautomerism, base pairing, enzyme reactions, metabolic pathways, G proteins, caffeine biosynthesis

The 6-oxopurine xanthine (Xan, neutral form 2,6-diketopurine) differs from the corresponding 6-oxopurines guanine (Gua) and hypoxanthine (Hyp) in that, at physiological $\mathrm{pH}$, it consists of $\mathrm{a} \approx 1: 1$ equilibrium mixture of the neutral and monoanionic forms, the latter due to ionization of $\mathrm{N}(3)-\mathrm{H}$, in striking contrast to dissociation of the N(1)-H in both Gua and Hyp at higher pH. In xanthosine (Xao) and its nucleotides the xanthine ring is predominantly, or exclusively, a similar monoanion at physiological pH. The foregoing has, somewhat surprisingly, been widely overlooked in studies on the properties of these compounds in various enzyme systems and metabolic pathways, including, amongst others, xanthine oxidase, purine phosphoribosyltransferases, IMP dehydrogenases, purine nucleoside phosphorylases, nucleoside hydrolases, the enzymes involved in the biosynthesis of caffeine, the development of xanthine nucleotide-directed $G$ proteins, the pharmacological properties of alkylxanthines. We here review the acid/base properties of xanthine, its nucleosides and

\footnotetext{
Supported by the Polish Ministry of Science and Informatics (KBN, grant No. 3P04A02425, and BST-932/BF)

${ }^{\circledR}$ Corresponding author: D. Shugar, fax: (48 22) 658 4636; e-mail: shugar@ibb.waw.pl

Abbreviations: APRTase, adenine phosphoribosyltransferase; DHLP, dihydrolipoic acid; dOxo, 2'-deoxyoxanosine; Et, ethyl; HGPRTase, hypoxanthine-guanine phosphoribosyltransferase; Hyp, hypoxanthine; Me, methyl; $\mathrm{Me}_{2} \mathrm{SO}$, dimethylsulphoxide; NTP, nucleoside-5'-triphosphate; Oxa, oxanine; Oxo, oxanosine; PNP, purine nucleoside phosphorylase; PRPP, $\alpha$-D-5-phosphoribosyl-1-pyrophosphate; PRTase, purine phosphoribosyltransferase; SAR, structure-activity relationship; Xan, xanthine; Xao, xanthosine; XMP, xanthosine-5'-phosphate; XTP, xanthosine-5'-triphosphate.
} 
nucleotides, their $\mathrm{N}$-alkyl derivatives and other analogues, and their relevance to studies on the foregoing. Included also is a survey of the pH-dependent helical forms of polyxanthylic acid, poly(X), its ability to form helical complexes with a broad range of other synthetic homopolynucleotides, the base pairing properties of xanthine in synthetic oligonucleotides, and in damaged DNA, as well as enzymes involved in circumventing the existence of xanthine in natural DNA.

\section{CONTENTS:}

1. Introduction

2. Neutral and ionic forms of guanine, hypoxanthine and their nucleosides

3. Neutral and ionic forms of xanthine and xanthosine

3.1. Thioxanthines and their nucleosides and nucleotides

3.2. Monoanions of thioxanthines

4. Polyxanthylic acid, poly(X)

5. Complexes of poly(X) with potentially complementary polynucleotides

5.1. Complexes of poly(X) with poly(U) analogues

6. Base pairing of xanthine in DNA duplexes

7. Xanthine in natural nucleic acids

7.1. 2'-Deoxyoxanosine (dOxo)

8. Cellular mechanisms for eliminating xanthine from nucleic acids

8.1. (d)XTP pyrophosphohydrolases, (d)XTPase

8.2. Repair enzymes for xanthine lesions in DNA

9. Metabolic role of monoanion of xanthine, its nucleosides and nucleotides

10. Xanthine oxidase

11. Purine nucleoside phosphorylases (PNP) 11.1. Mammalian PNPs

11.2. E. coli PNPII (Xao phosphorylase, Ino-Xao phosphorylase)

11.3. PNP and arsenate reductase

12. Xanthine nucleotide-selective $\mathrm{G}$ proteins

13. Purine phosphoribosyltransferases (PRTases)

14. IMP dehydrogenase and GMP synthetase

15. Biosynthesis of caffeine

16. Alkylxanthines: pharmacological aspects

17. 7-Methylxanthosine-5' -diphosphate $\left(\mathrm{m}^{7} \mathrm{XDP}\right)$ and mRNA cap

18. References

\section{INTRODUCTION}

The 6-oxopurine, xanthine (Xan, 2,6-dioxopurine), and its nucleosides and nucleotides are involved in a variety of intracellular metabolic pathways as substrates and/or intermediates of numerous enzymes or enzyme systems, e.g. Xan, a substrate of both xanthine oxidase (XO) and xanthine dehydrogenase, is an intermediate in the formation, from Hyp, of urate, the end product of purine nucleotide catabolism. The initial methyl acceptor for caffeine biosynthesis in tea and coffee plants, a subject most recently reviewed, amongst others, by Ashihara and Suzuki (2004), is xanthosine (Xao) and/or xanthosine-5 -phosphate (XMP). XMP is an intermediate in the formation of GMP from IMP by IMP dehydrogenase. XTP is as efficient a phosphate donor as ATP for human deoxycytidine kinase (Datta et al., 1989). In purine salvage pathways, some purine phosphoribosyltransferases (PRTase) will accept xanthine, in several instances with high selectivity relative to other purines (Craig \& Eakin, 2000; el Kouni, 2003). Although XTP and $\mathrm{XXTP}$ are moderate to good in vitro substrates for some polymerases, Nature has excluded Xan as a constituent of RNA and DNA for reasons which will become clear below.

The foregoing examples are far from exhaustive. What is puzzling, and even somewhat disconcerting, is that, with a few rare exceptions, the structures of the monoanionic species of Xan, its nucleosides and nucleotides, and some of their biologically important N-methyl counterparts, all highly relevant to their properties in vivo, have been widely overlooked or simply ignored. We herein survey these properties, relative to those of the corresponding 6-oxopurines Gua 
and Hyp, and their 9-substituted analogues, which include Guo and Ino, followed by an examination of their behaviour in synthetic polynucleotides and natural nucleic acids, their substrate properties in various enzyme systems, and their involvement in some metabolic pathways.

\section{NEUTRAL AND IONIC FORMS} OF GUANINE, HYPOXANTHINE AND THEIR NUCLEOSIDES

As will be seen from what follows, it is pertinent to first recall the structures of the cationic, neutral and ionic species of the 6-oxopurines Gua and Hyp, and of their corresponding nucleosides Guo and Ino, depicted in Scheme 1.

The structures of all the foregoing, as shown, have been well documented (Shugar \& Psoda, 1990). In particular, it should be noted, from the $\mathrm{p} K_{\mathrm{a}}$ values for protonation and dissociation, that all of these exist predominantly as the neutral species at physiological $\mathrm{pH}$. The same applies to the corresponding nucleotides. Furthermore, both the neutral and monoanionic species of the purine bases Gua and Hyp additionally exhibit N(7)-H N(9)-H prototropic tautomerism (see Shugar \& Psoda, 1990).

\section{NEUTRAL AND IONIC FORMS OF XANTHINE AND XANTHOSINE}

The situation is quite different for Xan and its nucleosides and nucleotides. There is general agreement that the neutral forms of Xan and Xao in solution are 2,6-diketo, as shown in Scheme 2 (Shugar \& Psoda, 1990), supported by the infrared spectrum of ${ }^{18} \mathrm{O}$-labeled Xao and 1-methyl-Xao in solution earlier reported by Roy \& Miles (1983), and by
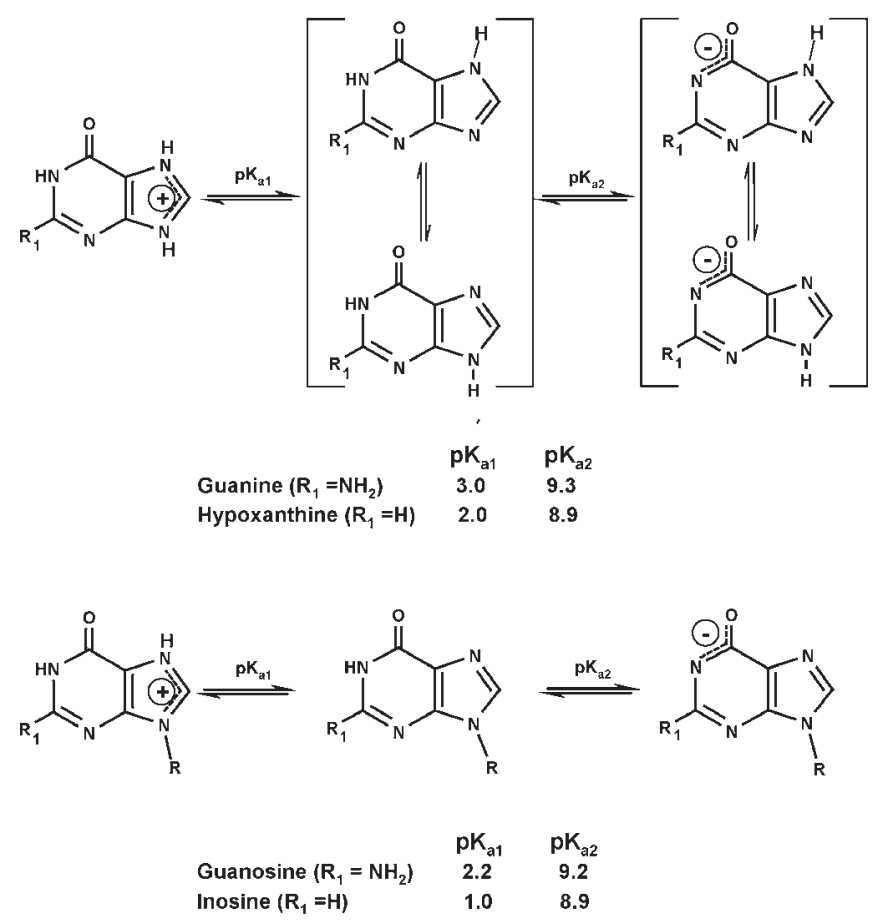

$\mathrm{R}=$ ribose

Scheme 1. Structures of the cationic, neutral and monoanionic forms of guanine (Gua) and hypoxanthine (Hyp), and guanosine (Guo) and inosine (Ino).

Note the 6-keto structures at physiological pH, and 6-enolate structures of the monoanions. Note also the N(7)-H $\mathrm{N}(9)-\mathrm{H}$ prototropic tautomerism of the neutral and monoanionic forms. 
multi-dimensional NMR spectroscopy of Xao in $\mathrm{Me}_{2} \mathrm{SO}$ and in aqueous medium (Poznanski et al., 2003).

Additional evidence for the 2,6-diketo form of neutral Xao was provided by Roy \& Miles the basis of the displacement of the $\mathrm{C}(8)-\mathrm{H}$ signals in the NMR spectra of Xan and 1-methyl-Xan, that the monoanions of both of these may be a mixture of two tautomeric species with ionization of both the N(3)-H and
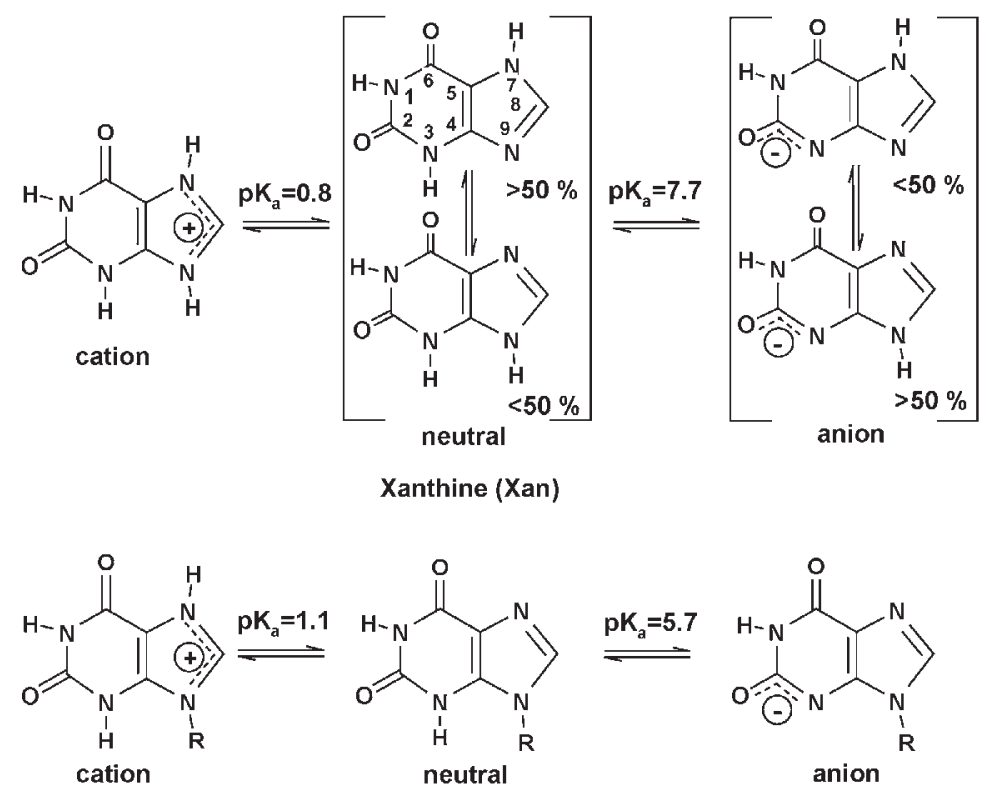<smiles>O=c1[nH]c(=O)c2ncn([TlH])c2[nH]1</smiles><smiles>[2H]n1cnc2c1ncn2-c1ccccc1</smiles>

Xanthosine (Xao)

Scheme 2. Structures of the neutral and monoanionic forms of xanthine (Xan) and xanthosine (Xao).

Note that dissociation of the N(3)-H affects the prototropic tautomeric equilibrium N(9)-H N(7)-H, and that the monoanions of Xan and Xao are still 6-oxopurines, like the neutral forms of Gua and Guo, and Hyp and Ino (see Scheme 1).

(1983) from the virtual identity of the $\mathrm{pH}$-dependent UV spectra of 1-methyl-Xao and 1,9-dimethyl-Xan, and the close resemblance of the spectrum of isocaffeine, 1,3,9-trimethyl-Xan, with those of the neutral forms of 1-methyl-Xao and XMP. The structure of Xao in the solid state is 2,6-diketo (Lesyng et $a l ., 1984)$, as is also N(1)-allyl-Xao, albeit the latter is in the syn conformation (Liaw et al., 1992).

There are, however, conflicting reports as regards the nature of the monoanionic species, e.g. Albert \& Brown (1954) reported a $\mathrm{p} K_{\mathrm{a}}$ of 7.3 for Xan, postulated to be due to dissociation of the N(1)-H, as for Gua and Hyp (see Scheme 1). Christensen et al. (1970) implicitly assumed that the monoanions of both Xan and Xao are due to dissociation of the N(1)-H. Lichtenberg et al. (1971) proposed, on
N(7)-H. More recently, Sau et al. (2000) ascribed formation of the monoanion of 1-methyl-Xan, with a $\mathrm{p} K_{\mathrm{a}}$ of 7.7 , to dissociation of the N(9)-H.

We have compiled from literature sources the most probable $\mathrm{p} K_{\mathrm{a}}$ values for monoanion (and dianion) formation in Xan, Xao, XMP, and related N-methyl and other derivatives, which are relevant to establishment of the nature of their monoanions, and hence of the relative substrate properties of the neutral and monoanionic species in various enzyme systems and metabolic pathways. These, some of which we have checked by spectrophotometric titration, are compiled in Table 1.

It should further be noted that, when reference is made throughout the text to the monoanion of a xanthosine nucleotide, e.g. 
XMP, this refers to the monoanion of the xanthine moiety, and not to the phosphate group.

It was initially proposed by Cavalieri et al. (1954), on the basis of the pH-dependent UV absorption spectra, and $\mathrm{p} K_{\mathrm{a}}$ values for monoanion formation, of a number of N-methyl de- assigned to the N(7)-H by Lichtenberg et al. (1971). Dissociation of the N(3)-H in Xan and Xao has been unequivocally confirmed in several laboratories, e.g. by Roy and Miles (1983) with the aid of infrared spectroscopy, and the use of various synthetic analogues, including ${ }^{18}$ O-labeled derivatives to identify the pres-

Table 1. Dissociation constants, $\mathrm{p} K_{\mathrm{a} 1}$ for monoanion formation, and $\mathrm{p} K_{\mathrm{a} 2}$ for dianion formation, and sites of dissociation, of xanthine, methylated xanthines, and related compounds $\mathbf{s}^{\mathrm{a}}$

\begin{tabular}{lllll}
\hline Compound & $\mathrm{p} K_{\mathrm{a} 1}$ & $\mathrm{Site}$ & $\mathrm{p} K_{\mathrm{a} 2}$ & Site \\
\hline Xanthine & 7.7 & $\mathrm{~N}(3)$ & 11.65 & $\mathrm{~N}(7,9)$ \\
1-methyl- & 7.7 & $\mathrm{~N}(3)$ & 12.1 & $\mathrm{~N}(7,9)$ \\
3-methyl- & 8.3 & $\mathrm{~N}(1)$ & 11.6 & $\mathrm{~N}(7,9)$ \\
7-methyl- & 8.35 & $\mathrm{~N}(3)$ & $13{ }^{\mathrm{b}}$ & $\mathrm{N}(1)$ \\
9-methyl- & 6.3 & $\mathrm{~N}(3)$ & 10.5 & $\mathrm{~N}(1)$ \\
1,3-dimethyl- & 8.8 & $\mathrm{~N}(7,9)$ & - & - \\
1,7-dimethyl- & 8.6 & $\mathrm{~N}(3)$ & - & - \\
1,9-dimethyl- & 6.3 & $\mathrm{~N}(3)$ & - & - \\
3,7-dimethyl- & 9.9 & $\mathrm{~N}(1)$ & - & - \\
3,9-dimethyl- & 10.5 & $\mathrm{~N}(1)$ & - & - \\
Xanthosine & 5.7 & $\mathrm{~N}(3)$ & 13 & - \\
1-methyl- & 5.85 & $\mathrm{~N}(3)$ & $\mathrm{cd}$ & - \\
$0^{6}$-methyl- & 6.15 & $\mathrm{~N}(3)$ & $\mathrm{nd}$ & - \\
5'-phosphate & 5.7 & $\mathrm{~N}(3)$ & $\mathrm{nd}$ & - \\
\hline
\end{tabular}

${ }^{\mathrm{a} R o u n d e d-o u t ~ v a l u e s ~}( \pm$ 0.1) compiled from various sources, including Ogston (1935), Cavalieri et al. (1954), Lichtenberg et al. (1971), Bergmann \& Dickstein (1955), Pfleiderer \& Nübel (1961), Christensen et al. (1970), Roy \& Miles (1983), many of them checked by spectrophotometric titration in our laboratories. ${ }^{\mathrm{b}}$ This compound is reported to decompose at highly alkaline $\mathrm{pH}$ (Lichtenberg et al., 1971). ${ }^{\mathrm{C}}$ It should be noted that, unlike the corresponding 9-methylxanthine, the ribose cis-hydroxyls of the ribosides also dissociate in this $\mathrm{pH}$ range, with $\mathrm{p} K_{\mathrm{a}} \approx 12.3$ (Remin et al., 1976); nd, not determined.

rivatives of Xan, that monoanion formation in both Xan and Xao is due to dissociation of the N(3)-H, as shown in Scheme 2. Support for this was forthcoming from the demonstration by Mizuno et al. (1969) that, in crystals of the monoanion of Xan, it is the N(3)-H which is dissociated, although the authors assumed that the monoanion is represented by the $\mathrm{N}(9)-\mathrm{H}$ prototropic tautomer, as earlier suggested for the monoanion in solution (Pfleiderer \& Núbel, 1961), but subsequently ence or absence of band frequencies of the carbonyl groups. Suzuki et al. (2000) demonstrated the absence of an $\mathrm{N}-\mathrm{H}$ signal in the ${ }^{1} \mathrm{H}$ NMR spectrum of 1-methyl-Xao in slightly alkaline medium, testifying to dissociation of the N(3)-H, subsequently extended and amply confirmed by multidimensional NMR spectroscopy of Xao over a broad $\mathrm{pH}$ range (Poznanski et al., 2003). The identity of the $\mathrm{p} K_{\mathrm{a} 1}$ values for Xan and 1-methyl-Xan (Table 1) further suggests that the monoanion of 
the latter is also due to dissociation of the $\mathrm{N}(3)-\mathrm{H}$. The closely similar $\mathrm{p} K_{\mathrm{a} 1}$ values for Xao (5.7) and 1-methyl-Xao (5.85), and for $O^{6}$-methyl-Xao (6.15), where only N(3)-H dissociation can occur, is further evidence for dissociation of the N(3)-H in Xao, as well as in XMP (Roy \& Miles, 1983), further supported by the results of $a b$ initio quantum mechanical calculations (Poznanski et al., 2003).

In a more recent theoretical study, Rogstad et al. (2003) applied quantum mechanical methods, using density functional theory with the B3LYP functional and the $6-31 \mathrm{G}^{++} \mathrm{G}^{* *}$ basis set, to calculate the microscopic dissociation constants, and the resultant $\mathrm{p} K_{\mathrm{a}}$, for xanthine, which was evaluated as 6.9 , considered in good agreement with an experimental value of 7.44 , taken from the older literature. The agreement, however, is less satisfactory, bearing in mind the established $\mathrm{p} K_{\mathrm{a}}$ for xanthine, 7.7 (Table 1 ).

\subsection{Thioxanthines and their nucleosides and nucleotides}

Some of these compounds are of considerable interest, particularly as potential antimetabolites, described in various sections, below. For example, 6-thiopurines, such as 6-thiohypoxanthine and 6-thioguanine, are converted intracellularly by phosphoribosyltransferases (Section 13) to their corresponding 5 '-monophosphates, which inhibit several vital metabolic reactions, leading to induction of remission in patients with myelocytic and acute lymphocytic leukemia. Although of proven clinical utility, ongoing efforts are devoted to development of analogues with enhanced therapeutic efficacy, including thioxanthines, recently reviewed by Elgemeie (2003) and el Kouni (2003). It is of interest that 6-thioxanthine, the most extensively studied thioxanthine, was shown to be a promising candidate for gene therapy of cancer in combination with the Escherichia coli gpt gene (which encodes the enzyme xanthineguanine phosphoribosyl transferase), claimed to be a promising alternative to the combination of the $E$. coli thymidine kinase gene with Ganciclovir (Ono et al., 1997).

The structures of the neutral and monoanionic forms of 6-thioxanthine, and its $\mathrm{N}$-methyl derivatives, were long ago described by Lichtenberg et al. (1972), with the aid of UV and NMR spectroscopy. As expected, the neutral form of 6-thioxanthine is 6-thione2-keto. Shortly thereafter Twanmoh et al. (1973), implicitly assuming that the neutral forms of 2-thio-, 6-thio- and 2,6-dithio- xanthines are 2-thione-6-keto, 6-thione-2-keto, and 2,6-dithione, respectively, employed ${ }^{1} \mathrm{H}$ NMR spectroscopy for assignment of the $\mathrm{N}-\mathrm{H}$ signals of these compounds in $\mathrm{Me}_{2} \mathrm{SO}$ (and in $\mathrm{Me}_{2} \mathrm{SO}$ following addition of water), found to be consistent with the foregoing structures. In both studies, ${ }^{1} \mathrm{H}$ NMR spectroscopy pointed to predominance of the $\mathrm{N}(7)-\mathrm{H}$ prototropic tautomer at neutral $\mathrm{pH}$.

\subsection{Monoanions of thioxanthines}

Particularly interesting are the monoanionic forms of these compounds, relative to those of xanthine. As in the case of xanthine, 1-methylxanthine and 9-methylxanthine, monoanion formation is due to dissociation of the N(3)-H. And, as might have been anticipated, Lichtenberg et al. (1972) found that all $\mathrm{p} K_{\mathrm{a}}$ values for monoanion formation in 6-thioxanthine and its $\mathrm{N}$-methyl derivatives were appreciably lower than for the corresponding xanthines (see Table 2). It follows that the monoanionic species of the thioxanthines are much more predominant at neutral $\mathrm{pH}$ than those of the corresponding xanthines, e.g. xanthine ( $K_{\mathrm{a}} 7.7$, Table 1$)$ exists at physiological $\mathrm{pH}$ as about a 1:1 mixture of the neutral and monoanionic forms, whereas 6-thioxanthine ( $\mathrm{p} K_{\mathrm{a}}$ about 6.2) is $>$ $95 \%$ as the monoanion.

The $\mathrm{p} K_{\mathrm{a}}$ of 6 -thioxanthosine has, to our knowledge, not been reported. However, for 9-methyl-6-thioxanthine, its $\mathrm{p} K_{\mathrm{a}}$ of 4.9 indicates that the $\mathrm{p} K_{\mathrm{a}}$ for 6 -thioxanthosine should 
be about 5 , or even lower. This follows from the fact that the $\mathrm{p} K_{\mathrm{a}}$ of 9-methylxanthine is 6.3 as compared to 5.7 for xanthosine (see Table 1). Consequently, at physiological $\mathrm{pH}$ (7.4), 6-thioxanthosine (and 6-thio-XMP) must exist almost exclusively as the monoanions.

Insofar as we are aware, the structures of 2-thioxanthine and, to our knowledge, the hitherto unknown 2-thioxanthosine, have not
Monny, 1966; Fikus \& Shugar, 1969; Torrence et al., 1977).

In aqueous medium the structure of $\operatorname{poly}(\mathrm{X})$ itself is rather complex and exhibits more than one ordered form, depending on the $\mathrm{pH}$ of the medium, and clearly related to ionization of the $\mathrm{N}(3)-\mathrm{H}$ of the xanthine residues. The most comprehensive study of its ordered structures in aqueous solution was conducted

Table 2. Dissociation constants, $\mathrm{p} K_{\mathrm{a} 1}$, for monoanion formation, and $\mathrm{p} K_{\mathrm{a} 2}$ for dianion formation, of 6-thioxanthine and its $\mathrm{N}$-methyl analogues, and proposed sites of dissociation ${ }^{\mathrm{a}}$

\begin{tabular}{lllll}
\hline Compound & $\mathrm{p} K_{\mathrm{a} 1}$ & $\mathrm{Site}$ & $\mathrm{p} K_{\mathrm{a} 2}$ & Site \\
\hline 6-Thioxanthine & $6.2^{\mathrm{b}}(7.7)^{\mathrm{c}}$ & $\mathrm{N}(3)$ & $11.4(11.6)^{\mathrm{c}}$ & $\mathrm{N}(7,9)$ \\
1-methyl- & $6.7(7.7)$ & $\mathrm{N}(3)$ & $11.0(12.7)$ & $\mathrm{N}(7,9)$ \\
3-methyl- & $7.9(8.3)$ & $\mathrm{N}(7,9)$ & $11.2(11.6)$ & $\mathrm{N}(1)$ \\
7-methyl- & $6.8(8.3)$ & $\mathrm{N}(3)$ & $12.1(13.1)$ & $\mathrm{N}(1)$ \\
9-methyl- & $4.9(6.3)$ & $\mathrm{N}(3)$ & $12.6(10.5)$ & $\mathrm{N}(1)$ \\
1,3-dimethyl- & $8.2(8.8)$ & $\mathrm{N}(7,9)$ & - & - \\
1,7-dimethyl- & $7.5(8.6)$ & $\mathrm{N}(3)$ & - & - \\
1,9-dimethyl- & $5.3(6.3)$ & $\mathrm{N}(3)$ & - & - \\
3,7-dimethyl- & $8.8(9.9)$ & $\mathrm{N}(1)$ & - & - \\
3,9-dimethyl- & $8.8(10.5)$ & $\mathrm{N}(1)$ & - & - \\
\hline
\end{tabular}

${ }^{\mathrm{a} D a t a}$ from Lichtenberg et al. (1972); ${ }^{\mathrm{b}}$ Stoychev et al. (2002) report a value of 6.5 ; ${ }^{\mathrm{c}}$ Values in brackets are for the corresponding parent xanthines, taken from Table 1.

been reported. Spectrophotometric titration demonstrated that the $\mathrm{p} K_{\mathrm{a}}$ of 2 -thioxanthine is 5.9 (Stoychev et al., 2002), so that it exists largely as the monoanion at physiological $\mathrm{pH}$, but its structure remains to be established.

\section{POLYXANTHYLIC ACID (poly(X))}

This polynucleotide, readily prepared enzymatically from XDP with the aid of polynucleotide phosphorylase, or from XTP with deoxynucleotidyl transferase, and available commercially, is of some interest because of its ability to form helical complexes with a broad range of potentially complementary polynucleotides (e.g. Michelson \& by Roy et al. (1979), with the aid of IR spectroscopy (to follow the $\mathrm{C}(2)$ and $\mathrm{C}(6)$ carbonyl band frequencies), and $\mathrm{pH}$ titration (with determination of the number of protons taken up or liberated per mole xanthine residues). This led, by a process of elimination of several hypothetical structures, to two proposed structures. One of these, in the $\mathrm{pH}$ range 6-9.5, was postulated to be a four-stranded helix, with bases linked by single hydrogen bonds, N(1)-H- - $-\mathrm{O}^{6}$, and the stability of which changes progressively with $\mathrm{pH}$ because of $\mathrm{N}(3)-\mathrm{H}$ ionization, but with no major changes in helix geometry. At $\mathrm{pH}$ about 7, the polymer is half-titrated, with two negative charges per tetramer. At $\mathrm{pH}$ 8.3, titration of the $\mathrm{N}(3)-\mathrm{H}$ is essentially complete, with uptake of one pro- 
ton/xanthine residue, and the polymer exhibits only a single carbonyl band at $1660 \mathrm{~cm}^{-1}$, identified as $\mathrm{C}(6)=0$. This structure possesses four negative charges per tetramer, and electrostatic repulsion between monomers is screened by internal counterions. Below $\mathrm{pH} 5$, a remarkably stable and quite different structure was observed, proposed to be a six-stranded helix in which both carbonyl oxygens and both $\mathrm{N}-\mathrm{H}$ protons of each residue are hydrogen bonded.

Strikingly different conclusions were reached by Arnott et al. (1981), who succeeded in drawing fibres of the potassium salt of poly $(\mathrm{X})$ at two $\mathrm{pH}$ values, 5.7 and 8 . In both instances, the fibres exhibited good X-ray diffraction patterns, each fully consistent with its existence as an antiparallel duplex form. The fibres drawn at $\mathrm{pH} 5.7$ occurred with nearest neighbour molecules spaced at 2.11 $\mathrm{nm}$, an axial translation per residue of $\mathrm{h}=$ $0.301 \mathrm{~nm}$, and a rotation per residue of $t=$ $36^{\circ}$. The intensity distribution of the diffraction pattern was quite close to that of A-RNA, for which $h=0.281 \mathrm{~nm}$ and $t=32.7^{\circ}$. By contrast, the fibres drawn at $\mathrm{pH} 8$ exhibited a less compact, statistically disordered, crystal packing, with nearest neighbors separated by $2.35 \mathrm{~nm}, \mathrm{~h}=0.252 \mathrm{~nm}$ and $\mathrm{t}=32.7^{\circ}$, and an intensity distribution identical to that for A-DNA, for which $\mathrm{h}=0.256 \mathrm{~nm}$ and $\mathrm{t}=32.7^{\circ}$. Both duplexes exhibited the same symmetry as Watson-Crick base pairs, but with the $\mathrm{C}\left(1^{\prime}\right) \cdots \mathrm{C}\left(1^{\prime}\right)$ distances $0.2 \mathrm{~nm}$ greater. On the assumption that triple hydrogen-bonded base pairs would be highly favoured, and lead to suppression of ionization of the residues, it was concluded that the duplex formed at $\mathrm{pH}$ 5.7 involves pairing of the enolic form of xanthine residues. For the structure formed at $\mathrm{pH} 8$, triple hydrogen-bonded base pairs were also considered to predominate, with hydrogen bonding to either a negatively charged $\mathrm{N}(3)$ or a neutral enolate $\mathrm{O}^{2}$ of one base, hence only $50 \%$ of the residues in the form of monoanions. The authors did not exclude the possibility of existence of multi- ple-stranded structures in aqueous solution. But, although the diffraction data provide compelling evidence for existence of poly(X) fibres as twin-stranded structures, the proposed existence of the enolic form of xanthine residues in base pairing is highly questionable, and quite inconsistent with the infrared data presented by Roy et al. (1979; 1983), demonstrating the total absence of the $\mathrm{C}(2)=\mathrm{O}$ in solution at alkaline $\mathrm{pH}$. We propose, instead, the following base pairing patterns for the neutral and alkaline forms of duplex $\operatorname{poly}(\mathrm{X})$ fibres (Scheme 3).

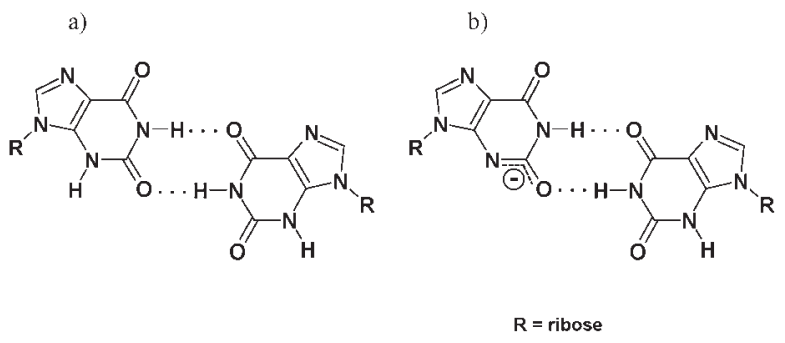

Scheme 3. Proposed base pairing in the neutral and monoanionic forms of antiparallel duplex poly(X) fibres.

(a) Neutral form with non-ionized base pairs; (b) with $50 \%$ of the xanthine residues ionized, by dissociation of the N(3)-H, adapted from Arnott et al. (1981). But see text for details and discussion. Note that base pairing involves the xanthine $\mathrm{C}(2)=\mathrm{O}$ (left) and $\mathrm{C}(6)=\mathrm{O}$ (right) in each pair of molecules, but rotation of the xanthine rings on the left side of each pair by $180^{\circ}$ about an axis through $\mathrm{O}^{6}$ and $\mathrm{N}(7)$ will lead to inverse autoassociates via the xanthine $\mathrm{C}(6)=\mathrm{O}$ and $\mathrm{N}(1)=\mathrm{H}$, respectively.

\section{COMPLEXES OF poly(X) WITH POTENTIALLY COMPLEMENTARY POLYNUCLEOTIDES}

Poly(X) has been reported to be extremely versatile in forming multi-stranded helical structures with a variety of synthetic polynucleotides (Michelson \& Monny, 1966; Fikus \& Shugar, 1969; Torrence et al., 1977; Roy et al., 1983). We limit ourselves here to complexes 
with poly(U) and analogues of the latter containing 5-substituted uracil residues.

\subsection{Complexes of poly(X) with poly(U) and $\operatorname{poly}(\mathrm{U})$ analogues}

Formation of such complexes, initially reported for poly(X):poly(U) by Michelson and Monny (1966), was more extensively investigated by Fikus and Shugar (1969). Surprisingly, no evidence could be found for formation of a complex of poly(X) with poly(U) at $\mathrm{pH} 5.2$, presumably due to the highly stable self-structure of poly(X) at acid $\mathrm{pH}$. By contrast, addition of a molar equivalent of $\operatorname{poly}(\mathrm{U})$ to $\operatorname{poly}(\mathrm{X})$ at $\mathrm{pH} 7.8$, where the xanthine residues of the latter are fully ionized, resulted in $20 \%$ hypochromicity at 255
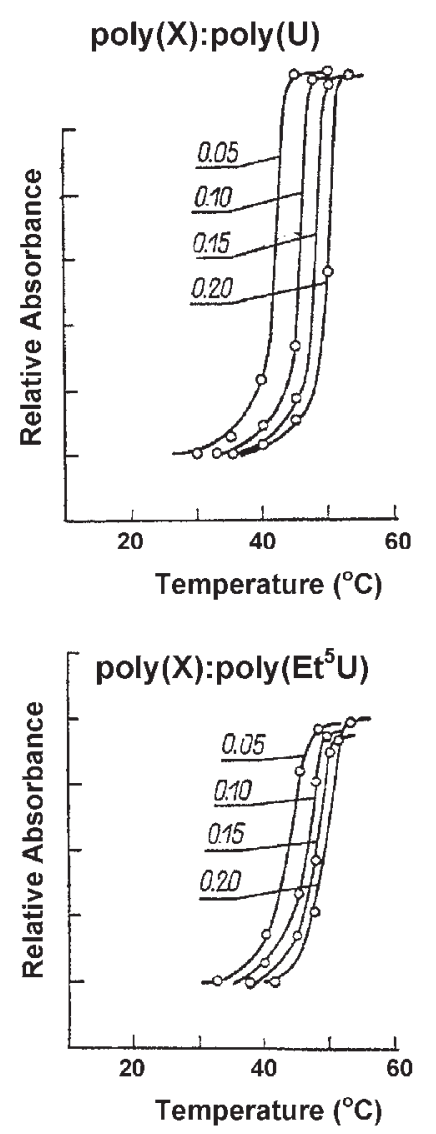

$\mathrm{nm}$, testifying to formation of a complex. The remarkably sharp melting profiles in the presence of various concentrations of $\mathrm{Na}^{+}$are displayed in Fig 1. Addition of an excess of poly(U) or poly $(\mathrm{X})$ revealed the profile of the excess of one or the other superimposed on that of poly(X):poly(U). Similar profiles were exhibited by 1:1 complexes of poly(X) with $\operatorname{poly}(\mathrm{rT})$ (5-methyl-U), poly(EtU) (5-ethyl-U) and poly(FU) (5-fluoro-U), as shown in Fig. 1.

It will be noted that the melting temperature, $T_{\mathrm{m}}$, for $\operatorname{poly}(\mathrm{X})$ :poly $(\mathrm{rT})$ is $12^{\circ}$ higher than that for poly(X):poly(U), as previously observed for poly(A):poly(rT) relative to poly(A):poly(U) (Swierkowski et al., 1965; Swierkowski \& Shugar, 1969). And replacement of poly(X):poly(rT) by poly(X):poly(EtU) leads to a decrease of $10^{\circ}$ in $T_{\mathrm{m}}$, as earlier re-
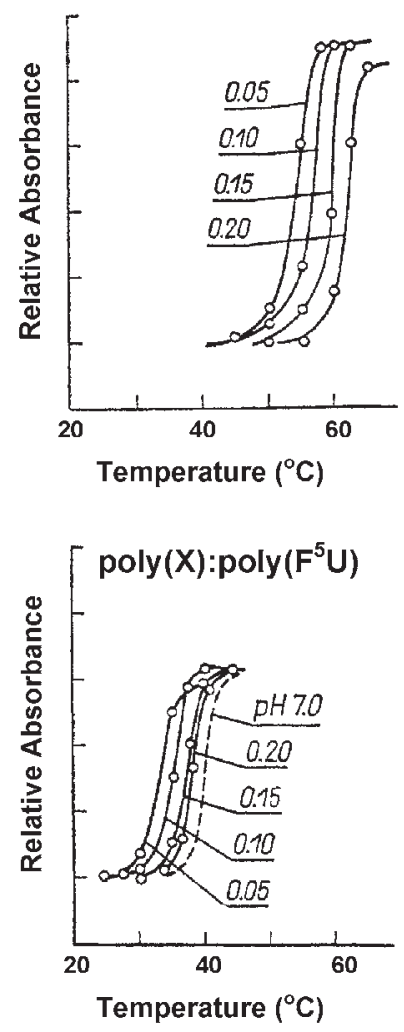

Figure 1. Melting profiles of 1:1 mixtures of poly(X) with poly(U), poly(rT) (5-methyl-U), poly(EtU) (5-ethyl-U) and poly(FU) (5-fluoro-U) in presence of various concentrations of $\mathrm{Na}^{+}$, in 0.01 M phosphate buffer pH 7.8 .

In the case of poly(X):poly(FU), the $\mathrm{p} K_{\mathrm{a}}$ of the $\mathrm{FU}$ residues is 7.8 , so that half of them are ionized at this $\mathrm{pH}$. Hence the profile of the complex in $0.2 \mathrm{M} \mathrm{Na}^{+}$was also run at $\mathrm{pH} 7$, where only about $15 \%$ of the residues are ionized. Adapted from Fikus \& Shugar (1969). 
ported for poly(A):poly(EtU) relative to poly(A):poly(U) (Swierkowski \& Shugar, 1969). Particularly interesting is poly(X): poly(FU), the $T_{\mathrm{m}}$ for which is about $10^{\circ}$ lower than for poly(X):poly(U). The 5-fluorouracil residues of poly(FU), with a $\mathrm{p} K_{\mathrm{a}}$ of 7.8 , are a mixture of neutral and monoanionic forms at this $\mathrm{pH}$. However, reduction of the $\mathrm{pH}$ to 7 , where only about $15 \%$ of the FU residues are in the form of the monoanion, did not affect the shape of the melting profile, with only a small increase in the $T_{\mathrm{m}}$ (see Fig. 1). It follows that, as previously reported for poly(A):poly(FU) (Szer \& Shugar, 1963), formation of the complex poly $(\mathrm{X})$ :poly(FU) is also accompanied by suppression of the ionization of the 5 -fluorouracil residues in poly(FU).

Bearing in mind existence of the xanthine residues of poly $(\mathrm{X})$ at $\mathrm{pH} 7.8$ as monoanions, the mode of base pairing proposed in duplexes of poly(X) with poly(U) and its analogues is as shown in Scheme 4. Such base pairing has been observed in synthetic polynucleotides containing an isolated xanthine residue in one strand with a thymine residue in the complementary strand (see below).

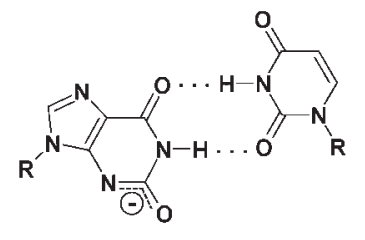

$\mathbf{R}=$ ribose

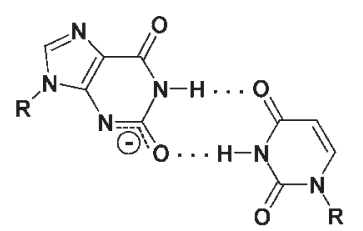

Scheme 4. Two possible modes of base pairing in the 1:1 complexes of $\operatorname{poly}(X)$ with $\operatorname{poly}(U)$, and poly(U) analogues with 5-substituted uracil residues, in alkaline medium, where the xanthine residues are ionized, due to dissociation of the N(3)-H.

Rather puzzling, however, was the finding that, under the foregoing conditions, poly(X) was unable to form complexes with poly(dU) or $\operatorname{poly}(\mathrm{dT})$.
The interaction of poly(X) with poly(U) was subsequently investigated in more detail by Roy et al. (1983), who confirmed, as above, that the two combine in equimolar proportions, but pointed out, correctly, that this does not constitute proof that the actual combining proportion is $1: 1$, and not a multiple of this ratio, e.g. a four-stranded $\mathrm{X}_{2} \mathrm{U}_{2}$, or a six-stranded $\mathrm{X}_{3} \mathrm{U}_{3}$, complex. The $\mathrm{X}: \mathrm{U}$ complex was found to exhibit a strikingly marked dependence of the melting temperature, $T_{\mathrm{m}}$, on the nature of the metal counterion present in the solution, e.g. in the presence $0.1 \mathrm{M}$ $\mathrm{Li}^{+}$the $T_{\mathrm{m}}$ was $33^{\circ} \mathrm{C}$ at $\mathrm{pH}$, whereas with $0.1 \mathrm{M} \mathrm{Rb}^{+}$the $T_{\mathrm{m}}$ was $56^{\circ} \mathrm{C}$, a phenomenon not observed with two-stranded nucleic acid helices. An additional unusual property of the $\mathrm{X}: \mathrm{U}$ complex was the increase in its stability with an increase in dissociation of the N(3)-H of the xanthine residues, attaining a plateau at $\mathrm{pH} 7$ (where dissociation is complete, as shown by the total absence of the xanthine $\mathrm{C}(2)=0$ by infrared spectrosocopy), and remaining constant beyond this point. Since ionization of the N(3)-H increases the charge density on the poly $(\mathrm{X})$ chains, the added electrostatic repulsion should lead to a decrease, and not the observed increase, in $T_{\mathrm{m}}$, indeed a strong, but not fully convincing, argument against a twin-stranded helix. This effect of various metal counterions is clearly deserving of further study of complexes of poly(X) with other polynucleotides. On the other hand, the mode of base pairing in the four-stranded helix proposed by Roy et al. (1983), involving single hydrogen bonds between bases, including the xanthine enolates, does not account for the specificity of base pairing proposed for a duplex (Scheme 4), also found to occur in synthetic oligonucleotides and nucleic acids containing xanthine residues, as described below. Further clarification of this problem is clearly predicated on the unequivocal establishment of the multiplicity of the poly(X):poly(U) complex, e.g. by sedimentation or low-angle X-ray scattering in solution. 


\section{BASE PAIRING OF XANTHINE IN DNA DUPLEXES}

The properties of DNA duplexes containing a single xanthine residue in one strand were examined by Eritja et al. (1986), bearing in mind that xanthine may appear in DNA as a product of spontaneous deamination of guanine, or reaction with reactive nitrogen species such as NO or nitrous acid (see review by Wilson et al., 2003). The duplexes were prepared by exploiting the ability of Drosophila the base pairing proposed earlier for duplexes of poly(X) with poly(U) and some poly(U) analogues (Scheme 4). Proposed modes of pairing for $\mathrm{X}: \mathrm{A}, \mathrm{X}: \mathrm{G}$ and $\mathrm{X}: \mathrm{C}$ are shown in Scheme 5, the legend to which comments on the proposed pairing of $\mathrm{X}: \mathrm{C}$.

Kamiya et al. (1992) extended the findings of Eritja et al. (1986) by profiting from the fact that any point mutation at the second position of codon 12 of the c-Ha-ras gene leads to focus forming activation of the gene. They therefore introduced dXao into this position

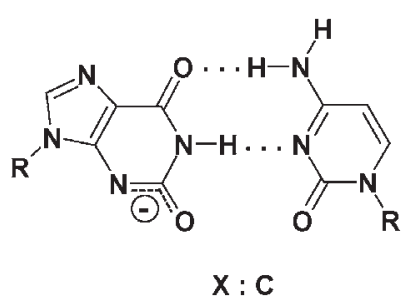

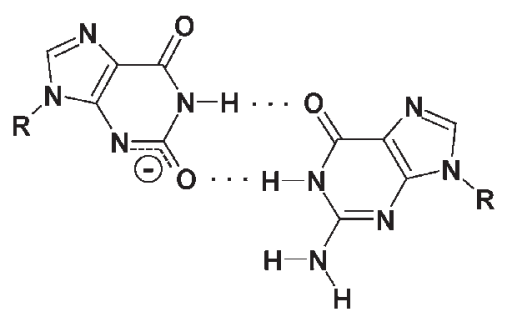

$X: G$

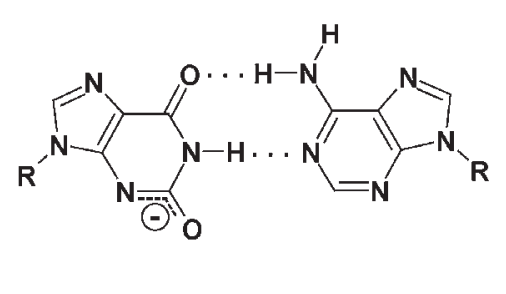

$\mathrm{X}: \mathrm{A}$

$\mathbf{R}=$ ribose

Scheme 5. Proposed base pairing, in a synthetic duplex oligonucleotide, of a Xan residue in one strand with a cytosine, guanine or adenine in the complementary strand (Eritja et al., 1986).

But note that for the proposed X:C pair, with the xanthine residue in the monoanionic form, due to dissociation of the $\mathrm{N}(3)-\mathrm{H}$, there will be electrostatic repulsion between the xanthine $\mathrm{C}(2)-\mathrm{O}^{-}$and the cytosine $\mathrm{C}(2)=\mathrm{O}$. However, rotation of the cytosine moiety by $180^{\circ}$ about an axis through the cytosine $\mathrm{C}(6)$ and $\mathrm{N}(3)$ will lead to reversed Watson-Crick pairing, with an ionic hydrogen bond between the $\mathrm{C}(2)-\mathrm{O}^{-}$and the cytosine $\mathrm{C}(4)-\mathrm{NH}_{2}$.

DNA pol- $\alpha$ (devoid of proof-reading 3 '-exonuclease activity) to incorporate natural dNTP substrates opposite a xanthine residue at a specific site in a nonadecanucleotide template. All four natural bases were found to undergo incorporation opposite xanthine, the relative rates being $\mathrm{T}>\mathrm{C} \gg \mathrm{A} \quad \mathrm{G}$, but not correlated with the relative thermodynamic stabilities of the resulting duplexes, from measurements of the $T_{\mathrm{m}}$ of the melting profiles (X:T > X:G > X:A and X:C). Two proposed possible modes of pairing of $\mathrm{X}: \mathrm{T}$ are similar to in the synthetic gene, followed by transfection of the gene into NIH3T3 cells. The dX-containing gene exhibited high transforming activity, and an almost exclusive mutation of $\mathrm{G}$ to $\mathrm{A}$ by the base analogue, indicating that dTMP was incorporated at the site opposite the $d X$ residue. The overall result, following generation of $\mathrm{dXao}$ by deamination of dGuo, was a mutation with a $\mathrm{G} \rightarrow \mathrm{A}$ transition, which may be directly involved in focus-forming activation of the ras gene. 
According to the proposal of Eritja et al. (1986) and Kamiya et al. (1992), the X:C base pair is formally similar to a Watson-Crick pair (Scheme 5), whereas the X:T pair is a wobble base pair, which may distort the duplex, hence not suitable for polymerization. However, because of destablization of the X:C pair (by electrostatic repulsion between the Xan $\mathrm{C}(2)-\mathrm{O}^{-}$and the cytosine $\mathrm{C}(2)=\mathrm{O}$, see Scheme 5), dTMP, as mentioned above, exhibited a higher rate of incorporation than dCMP opposite dXMP in vitro (Eritja et al., 1986), and was also readily incorporated in the mammalian system (Kamiya et al., 1992).

One of several comprehensive studies on the possible modes of base pairing of base analogues, including xanthine, in a synthetic DNA duplex is that of Benner and coworkers (Geyer et al., 2003), based on measurements of the $\mathrm{T}_{\mathrm{m}}$ of the melting profiles for the following duplexes,

\section{$5^{\prime}-\mathrm{CACN}_{\mathbf{a}}$ ACTTTCTCCT-3' \\ $3^{\prime}-$ TGTGN $_{\mathrm{b}}$ TGAAAGAGG-5',}

where $\mathbf{N}_{\mathbf{a}}$ and $\mathbf{N}_{\mathbf{b}}$, each located in the interior of the helix to avoid end effects, represent the position of the appropriate base analogue. Since paired bases may have perturbed $\mathrm{p} K_{\mathrm{a}}$ values, e.g. protonation of imino nitrogens at slightly acid $\mathrm{pH}$, leading to modifications of H-bonding, $T_{\mathrm{m}}$ values were followed at both $\mathrm{pH} 7.9$ and 5.4. This choice of $\mathrm{pH}$ values also proved appropriate for following the role of the monoanion of the xanthine ring in XMP, with a $\mathrm{p} K_{\mathrm{a}}$ of 5.7 , hence fully ionized at $\mathrm{pH}$ 7.9. Although not shown, all duplexes with different $\mathbf{N s}$ were reported to display smooth single-melting transitions, consistent with two-state melting. It would have been useful if the authors had included the half-breadths $\left(\Delta T_{\mathrm{m}}\right)$ of the melting profiles, to permit better assessment of the transitions.

With duplexes containg natural bases, or various base analogues, paired with Xan in one of the strands, the $T_{\mathrm{m}}$ values were found to increase by $2-5^{\circ} \mathrm{C}$ on going from $\mathrm{pH} 7.9$ to 5.4 , consistent with the assumption that a negative charge on Xan decreases the stability of the duplex at alkaline $\mathrm{pH}$. This was reinforced by the finding that replacement of Xao by a dXao analogue, 7-deaza-2'-deoxyxanthosine (erroneously referred to as dX), which has a $\mathrm{p} K_{\mathrm{a}}$ of 7.2 (Seela et al., 1985), so that more of the neutral form is present at $\mathrm{pH} 7.9$, led to increases in $T_{\mathrm{m}}$ values of $3-5^{\circ} \mathrm{C}$. It should, however, be noted that, unlike xanthosine, it is not known whether ionization of 7-deazaxanthosine is due to dissociation of the N(1)-H or N(3)-H, which may well affect conclusions regarding its mode of base pairing.

Bearing in mind the ability of poly(X) to form helical structures in solution, and antiparallel duplexes when drawn as fibres (Section 4), it is of interest that, in line with results for the foregoing, an X:X pair was $4^{\mathrm{O}}$ more stable at acid $\mathrm{pH}$.

\section{XANTHINE IN NATURAL NUCLEIC ACIDS}

Xanthine residues in synthetic polynucleotides have been shown to be capable of base pairing with all four natural bases of DNA (see Section 6). Furthermore, XTP and dXTP are moderate to good substrates for some polymerases, examples of which are cited below. An extensive list of references to recognition of XTP and dXTP, both as substrates and as components of templates, by various RNA and DNA polymerases, will be found in a report by Rogstad et al. (2003). Nonetheless, xanthine is not a normal constituent of nucleic acids. One compelling reason for this is the existence of both XTP and XXTP at physiological $\mathrm{pH}$ with the Xan base predominantly in the form of a monoanion, and in equilibrium with a minor proportion of the neutral form, hence likely to affect fidelity of replication and transcription. 
It has also been widely assumed that the glycosidic bond of dXao is inherently unstable, leading to rapid depurination, even at neutral pH (Lindahl, 1993; Suzuki et al., 1997). This was recently questioned by two groups. Wuenschell et al. (2003) examined the rate of depurination of a Xan residue incorporated at position 10 in a single-stranded 34mer oligodeoxynucleotide at acid and neutral $\mathrm{pH}$. As expected, depurination was very rapid at acid $\mathrm{pH}$. But at $\mathrm{pH} 7$ the rate of depurination was virtually identical with that for a guanine residue located at the same position. Concurrently, and independently, Vongchampa et al. (2003), reported that dXao itself has a half-life of about 50 days at $\mathrm{pH}>7$ and $37^{\circ} \mathrm{C}$. Its stability is further substantially enhanced when it is a constituent of single-stranded and duplex oligonucleotides. At $\mathrm{pH} 7$ and $37^{\circ} \mathrm{C}$, an incorporated dXao residue in a 30mer oligodeoxynucleotide was estimated to have a half-life of 2 years. Additional evidence for the stability of Xan residues was provided by the melting profile of a $30 \mathrm{mer} \mathrm{du}$ plex oligodeoxynucleotide containing a single dXao residue in one strand. When paired with $\mathrm{dCyd}$ in the complementary strand, the melting profile exhibited a $T_{\mathrm{m}}$ of $73^{\circ} \mathrm{C}$. Replacement of the dXao residue by dIno or dGuo gave $T_{\mathrm{m}}$ values of $74^{\circ} \mathrm{C}$ and $78^{\circ} \mathrm{C}$, respectively. The small $\left(5^{\circ} \mathrm{C}\right)$ decrease in duplex stability on changing from a G:C base pair to $\mathrm{X}: \mathrm{C}$ was considered due to the negative charge on Xan residues (Vongchampa et al., 2003). The authors did not follow the mobility of the oligodeoxynucleotides in a gel, which would have furnished additional evidence for their conclusions. It had, in fact, much earlier been demonstrated by Piccirilli et al. (1990) that, following incorporation of a Xan residue in a synthetic primer/template by the Klenow fragment of DNA polymerase I at physiological $\mathrm{pH}$, the resulting product migrated faster on a gel than the analogous products containing Gua or Ade in place of Xan. A similar finding was subsequently reported by Suzuki et al. (1998).
There is, on the other hand, ample evidence that oxidative deamination of bases in DNA, including spontaneous deamination, which leads to conversion of $\mathrm{dCyd}$ to $\mathrm{dUrd}$, and dAdo to dIno, also results in the formation of dXao from dGuo (Suzuki et al., 1997). These deamination products are also produced by reactive nitrogen species generated by ionizing radiations, as well as endogenous genotoxins, especially nitric oxide (NO), which reacts readily with $\mathrm{O}_{2}$ to produce nitrous anhydride, $\mathrm{N}_{2} \mathrm{O}_{3}$, a potent nitrosating agent which has been proposed to deaminate aromatic amines via an aryl diazonium ion intermediate (Caulfield et al., 1998). Whereas dGuo is much less susceptible to hydrolytic deamination than $\mathrm{dCyd}$ and dAdo, deamination of Gua to Xan by $\mathrm{N}_{2} \mathrm{O}_{3}$ was reported to proceed at twice the rate of that for Cyt and Ade. On exposure of human lymphoblastoid TK6 cells to NO, the resulting level of Xan residues in DNA was found to be 40-fold higher than that from untreated control cells (Nguyen et al., 1992).

\subsection{2'-Deoxyoxanosine (dOxo)}

Quite intriguing was the finding that the reaction of dGuo with nitrous acid or nitric oxide resulted in formation, in addition to the expected major product $\mathrm{dXao}$, of an additional product, 2 -deoxyoxanosine (dOxo), shown in Scheme 6 (Suzuki et al., 1997). It should be noted that it is a formal structural analogue of 2 -deoxyisoguanosine. The corresponding riboside, oxanosine (Oxo), had much earlier been isolated as a novel antibiotic from a strain of Streptomyces capreolus. Its deoxynucleoside dOxo was subsequently chemically synthesized and found to exhibit more potent antiviral and antitumor activities than the parent riboside (Suzuki et al., 1997).

Incubation of an aerated solution of dGuo in the presence of $\mathrm{NO}$ at neutral $\mathrm{pH}$ also led to the appearance of dOxo. Since many cell types produce endogenous NO, it is to be ex- 
pected that this would lead to generation, in addition to $\mathrm{dXao}$, of dOxo from dGuo residues in DNA. In accordance with the earlier proposed mechanism for formation of such products (Caulfield et al., 1998), cited above, Suzuki et al. (2000) succeeded in isolating, from a guanosine- $\mathrm{HNO}_{2}$ reaction system, of a
dOxo residues (Suzuki et al., 1997). This, in conjunction with the stability of these residues, and consequent lack of formation of apurinic sites, would exclude a base excision repair pathway for such lesions unless there existed a DNA glycosylase for the base moiety of dOxo residues.

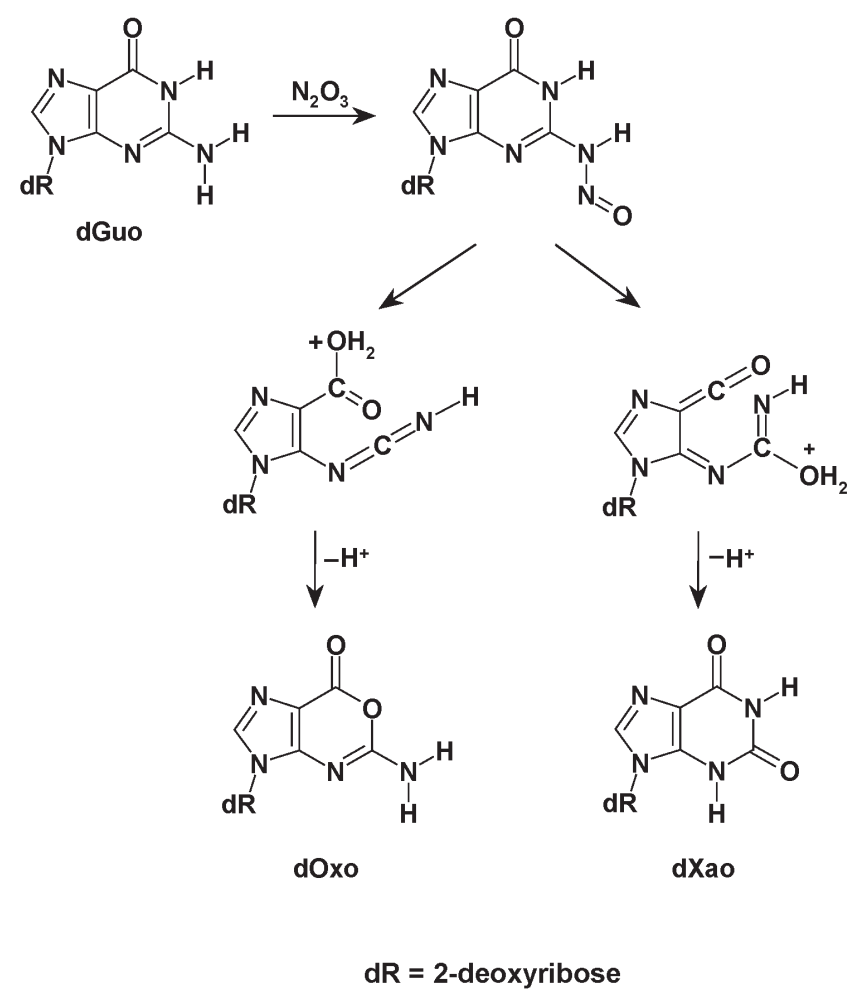

Scheme 6. Formation of $2^{\prime}$-deoxyoxanosine (dOxo) and $2^{\prime}$-deoxyxanthosine (dXao) from the reaction of $\mathbf{2}^{\prime}$-deoxyguanosine (dGuo) with nitrous acid.

Only the partial pathways are shown. See Suzuki et al. (1997) for full details.

short-lived intermediate $\left(t_{1 / 2} \quad 6 \mathrm{~min}\right)$, tentatively identified as a diazotate of Guo. This intermediate underwent conversion via two independent pathways to oxanosine and Xao (Scheme 6) in the ratio 1:4. With dGuo, the products were dOxo and dXao in a similar ratio. Furthermore the N-glycosidic bond of a dOxo residue in a synthetic oligonucleotide was found to be as stable as that of dGuo, and much more so than that of dXao (Suzuki et al., 1997).

However, melting profiles of duplexes such as d(T5OxoT6):d(A6NA5), where $\mathrm{N}=\mathrm{A}, \mathrm{G}, \mathrm{C}$ or $\mathrm{T}$ ), exhibited relatively low $T_{\mathrm{m}}$ values, pointing to poor base pairing properties of
An additional genotoxic mechanism of NO-induced DNA damage has been postulated from the finding that presence of an oxanine (Oxa) residue in DNA results in formation of DNA-protein cross-links (Nakano et al., 2003). Incubation of duplex DNA containing an Oxa residue at a site-specific position with DNA binding proteins such as histone, high-mobility group proteins, or DNA glycosylases, led to formation of DNA-protein cross links, especially with DNA glycosylases, between Oxa and the side-chains of lysine and arginine. In line with this, a HeLa cell extract gave rise to two major DNA-protein products when incubated with DNA containing Oxa. 


\section{CELLULAR MECHANISMS FOR ELIMINATING XANTHINE FROM NUCLEIC ACIDS}

\section{1. (d)XTP pyrophosphohydrolases, (d)XTPase}

It should be noted that intracellular oxidative deamination of DNA bases may occur not only in duplex DNA, but also in the free nucleotide pool. It is, in fact, most likely that oxidative damage of DNA bases will occur more frequently in the nucleotide pool than in chromosomal DNA, followed by misincorporation into nucleic acids, leading to mutagenesis. Since Xan residues are not found in native DNA, mechanism(s) must exist for preventing such incorporation.

In this context, it was long ago demonstrated by Wang and Morris (1974) that various tissues of the rabbit harbour an NTP pyrophosphohydrolase activity which, purified about 700-fold from rabbit liver, with an $m$ about $37 \mathrm{kDa}$, exhibited a remarkable specificity for the non-canonical ITP, dITP and XTP. It was virtually inactive vs ATP (0.3\%), and exhibited very low activity vs UTP, TTP, GTP, dGTP, CTP and dCTP (0.3-9\%). It was proposed by the authors that the function of this enzyme is to prevent the incorporation of dITP and dXTP into DNA during replication, and of ITP and XTP into RNA during transcription. A rather unusual feature of this enzyme is its $\mathrm{pH}$ optimum, about 10 , where it was 6-fold more active than at $\mathrm{pH} 7.4$, but with the use of only ITP, and not XTP, as substrate (see also below).

The foregoing, which has hitherto attracted little attention, has now gained added significance following the isolation by Hwang et al. (1999) of a protein coded by a hypothetical gene, Mj0226, from the hyperthermophile Methanococcus jannaschii. The protein was crystallized, its 3D structure determined, and a search conducted for possible structural homologues in the Protein Data Bank. This led to identification of a number of homo- logues, which shared the property of binding nucleotides and nucleotide analogues. On conducting such binding studies, the protein was found to weakly hydrolyze GTP to GMP + $\mathrm{PP}_{\mathrm{i}}$, suggesting it is an NTPase. This, in turn, led to analysis of its activity against a broad range of natural (d)NTPs and various analogues, culminating in the finding (Chung et $a l ., 2001)$ that the enzyme exhibits a remarkable specificity for XTP, ITP and dITP, with $k_{\text {cat }} / K_{\mathrm{m}}$ values more than two to four orders of magnitude higher than for 20 other NTPs and analogues. Although dXTP was not available, the similar $k_{\text {cat }} / K_{\mathrm{m}}$ values for ITP (650) and dITP (610) suggest that dXTP is an equally good substrate. The enzyme was, furthermore, shown to be devoid of endonuclease and 3 -exonuclease activities. Its $\mathrm{pH}$ optimum, but with only dITP as substrate, was about 10.5 .

In line with its isolation from a hyperthermophile, the foregoing enzyme displayed an optimal temperature of $80^{\circ} \mathrm{C}$, hence similar to the optimum temperature for growth. At $30^{\circ} \mathrm{C}$, activity was 5 -fold lower. However, the same authors (Chung et al., 2001) prepared, by cloning and purification, two protein homologues of Mj0226, one from the hyperthermophile Archaeoglobus fulgidus, and a second from the mesophile $E$. coli. Both exhibited similar high specificities for XTP and dITP, with the $E$. coli enzyme activity followed at $37^{\circ} \mathrm{C}$.

Further in line with the above, Chung et al. (2002) cloned, purified and characterized a hypothetical 21-kDa protein (ORF 0197) from $E$. coli K-12. This protein, denoted as $E$. coli Ec0197, shares $33.5 \%$ sequence identity with the NTPase from $M$. jannaschii identified by Hwang et al. (1999), a similar specificity for ITP, dITP and XTP (and presumably dXTP), and a similar optimum $\mathrm{pH}$ about 10-10.5, extending even to 11 . At neutral $\mathrm{pH}$, activity was about $40 \%$ that at $\mathrm{pH} 10$. However, in contrast to other reports, dGTP and dUTP were reported to undergo hydrolysis at $\mathrm{pH} 10$ at about $10 \%$ the rate for XTP. 
Independently, Lin et al. (2001) identified the gene for a similar protein in human foetal brain. Cloning of its cDNA led to isolation of a 21.5-kDa protein with NTPase activity highly specific for ITP, dITP, dXTP, and again with an optimum $\mathrm{pH}$ of about 10 . The gene encoding the cDNA sequence of the human enzyme, referred to as ITPA, was localized on the short arm of chromosome 20p, and its mRNA transcripts were found in all 24 human adult tissues examined. Furthermore, a BLAST search revealed the existence of similar sequences in more than 40 proteins, and putative protein sequences, all about 200 amino acids in length, and with similar structures in organisms ranging from bacteria to mammals.

Bearing in mind the existence of such activities in organisms as widely divergent as two hyperthermophiles, $E$. coli, and the rabbit (Wang \& Morris, 1974), it would appear that, like the ubiquitous dUTPase, the function of which is to prevent the incorporation of uracil into DNA by hydrolysis of dUTP to dUMP, most or all organisms contain a (d)XTPase/ (d)ITPase to prevent incorporation of Xan and Hyp residues into DNA and RNA. One other such enzyme known is the MutT protein of $E$. coli, an NTPase which hydrolyzes 8-oxo-dGTP, a highly mutagenic oxidized nucleotide, to 8-oxo-dGMP and $\mathrm{PP}_{\mathrm{i}}$ (Bessman et al., 1996; Sekiguchi \& Tsuzuki, 2002).

One striking feature shared by all the foregoing enzymes is their unusual $\mathrm{pH}$ optimum, 10-11. At this strongly alkaline $\mathrm{pH}$, the Xan base of (d)XTP ( $K_{\mathrm{a}}$ about 5.7) exists exclusively as the monoanion, with dissociation of the N(3)-H (see Scheme 2); and the Hyp base of (d)ITP ( $\mathrm{pKa}$ about 9) is more than 90\% in the form of the monoanion, but in this case with dissociation of the N(1)-H (see Scheme 1). It should, however, be noted that in all instances the $\mathrm{pH}$ optimum was determined only with ITP or dITP as substrate. It would obviously be desirable to determine the $\mathrm{pH}$ optimum with (d)XTP.

\subsection{Repair enzymes for xanthine lesions in} DNA

Endonuclease V from $E$. coli, a product of the nif gene, which recognizes a broad spectrum of lesions in DNA, has been shown to recognize misincorporated dXao lesions (Schouten \& Weiss, 1999; He et al., 2000). Furthermore, under conditions where this enzyme recognizes dIno lesions in both single-stranded and double-stranded DNA, it proved to be active against dXao lesions only in duplex DNA, by cleavage of the strand containing the dXao lesion. Hence it appears to recognize the Xan residue as such, and not the accompanying mismatch with the base in the complementary strand (He et al., 2000). Isoguanine lesions were also recognized, but poorly.

Terato et al. (2002) subsequently examined the repair ability of the DNA N-glycosylases from $E$. coli for dXao and dOxo lesions in DNA. Both AlkA (3-methyladenine DNA glycosylase II) and endonuclease VIII recognized the presence of Xan residues, substantiated by following directly the release of $\left[{ }^{3} \mathrm{H}\right] \mathrm{Xan}$ from the DNA. Both enzymes exhibited a lower ability to excise the oxanine base of dOxo lesions.

The ability to repair Xan lesions in DNA by four enzymes of the base excision repair pathway was examined by Wuenschell et al. (2003), with the use of 34 mer oligodeoxynucleotide duplexes containing a Xan residue in one strand opposite to each of the four natural bases in the complementary strand. AlkA protein was found to be the most effective for removal of Xan from X:C base pairs, with lower activity vs X:T, X:G and $\mathrm{X}: \mathrm{A}$ pairs within the same sequence context. The human homologue of AlkA, the methylpurine glycosylase $\mathrm{Mpg}$, also displayed good specificity for excision of Xan from X:C pairs. 


\section{METABOLIC ROLE OF MONOANION OF XANTHINE, ITS NUCLEOSIDES AND NUCLEOTIDES}

We now consider the possible role of these monoanionic species, and related analogues, in various enzyme systems and metabolic pathways where their presence at high levels cannot be ignored. One of the simplest approaches would appear to be measurements of the $\mathrm{pH}$-dependence of a given enzymatic reaction in which they may be involved. However, the complexities, and the numerous pitfalls inherent in the interpretation, of the mechanism of an enzyme-catalyzed reaction from $\mathrm{pH}$-dependence of the kinetics are truly formidable, and have been frequently drawn attention to. The objectives of such studies include, amongst others, determination of $\mathrm{p} K_{\mathrm{a}}$ values approximating those of individual ionizable groups, the rate constants for specific ionic forms of the reactants, as well as their modification during the course of ligand binding, a subject comprehensively reviewed, amongst many others, by Brocklehurst (1994). Other approaches must frequently be employed to assist in a proper interpretation, e.g. rapid reaction techniques, fluorescence emission, the use of structurally related ligand analogues.

Similar considerations apply when the ligands involved (substrates, inhibitors) may exist in different tautomeric forms, e.g. the protomeric N(7)-H N(9)-H tautomers of the 6-oxopurines, the equilibrium of which is additionally dependent on whether the purine in question is in its neutral or anionic form (see Schemes 1 and 2).

\section{XANTHINE OXIDASE}

This enzyme and xanthine dehydrogenase, interconvertible (by proteolysis or disulfide formation) forms of the same gene product known as xanthine oxidoreductase, catalyzes the oxidation of many purines and related an- alogues. In mammalian systems it catalyzes the last two steps of purine catabolism, the oxidation of Hyp to xanthine and of Xan to uric acid. Its mechanism of action, which is very complex, has been extensively studied, in many instances with the use of non-physiological substrates. The reaction is initiated at a molybdenum-pterin center, from which electrons are transferred, with the mediation of two $\mathrm{Fe}_{2} \mathrm{~S}_{2}$ iron-sulphur centers, to the isoalloxazine system of flavine adenine dinucleotide (FAD), and finally to $\mathrm{NAD}^{+}$or, with production of the superoxide anion and $\mathrm{H}_{2} \mathrm{O}_{2}$, to molecular oxygen in the case of xanthine dehydrogenase and xanthine oxidase, respectively.

It is rather surprising that only very recently has attention been directed to the fact that, at physiological $\mathrm{pH}$, xanthine $\left(\mathrm{p} K_{\mathrm{a}} 7.7\right.$, see Table 1) is an approximately equilibrium mixture of the neutral and monoanionic species. In a very recent extensive theoretical study of the interaction of substrates and inhibitors with xanthine oxidase (Rastelli et al., 1997), based on similarity concepts and molecular modelling, consideration was limited exclusively to possible involvement of putative tautomers of only the neutral forms of the physiological substrates Hyp and Xan.

Kim et al. (1996) first demonstrated that, with xanthine as substrate, the steady-state kinetic parameter $k_{\text {cat }} / K_{\mathrm{m}}$ exhibited a symmetrical bell-shaped dependence on $\mathrm{pH}$ with a maximum at $\mathrm{pH} 7$, pointing to an ionizable group with $\mathrm{p} K_{\mathrm{a}}$ about 6.6 in the active site of the enzyme, and a second ionizable group with $\mathrm{p} K_{\mathrm{a}}$ about 7.4. In the latter $\mathrm{pH}$ range there is no known ionizable group in the enzyme, whereas the $\mathrm{p} K_{\mathrm{a}}$ of 7.4 is close to the $\mathrm{p} K_{\mathrm{a}}$ of the substrate Xan (7.7). This was taken to imply that the substrate must be in the protonated, i.e. neutral, form for catalysis to proceed, and considered consistent with the proposed reaction mechanism, involving proton abstraction from $\mathrm{C}(8)$ of xanthine, followed by hydroxylation (Hille, 1996). If the substrate were in the ionized form, its result- 
ing negative charge would destabilize the accumulating negative charge on $\mathrm{C}(8)$ in the course of deprotonation at this site. With the non-physiological substrate lumazine, a similar bell-shaped $\mathrm{pH}$ dependence was observed, with $\mathrm{p} K_{\mathrm{a}}$ values of 6.5 (hence similar to that with xanthine) and 7.8, the latter accounted for by the fact that the $\mathrm{p} K_{\mathrm{a}}$ of lumazine is 0.3 $\mathrm{pH}$ units higher than that of xanthine.

Subsequently Sau et al. (2000) reported that the $\mathrm{pH}$-dependence of $V_{\max } / K_{\mathrm{m}}$ for 1-methylxanthine exhibited a bell-shaped curve similar to that for xanthine, with corresponding $\mathrm{p} K_{\mathrm{a}}$ values of 6.2 and 7.7, and concluded, like Kim et al. (1996), that only the neutral form of 1-methylxanthine is the substrate. Although Kim et al. (1996) did not identify the nature of the monoanionic form of xanthine, Sau et al. (2000) erroneously ascribed it to dissociation of the N(1)-H, and the monoanionic form of 1-methylxanthine to dissociation of the $\mathrm{N}(9)-\mathrm{H}$. However, as pointed out above (Section 3), the monoanionic species of both are due to dissociation of the N(3)-H, with almost identical $K_{\mathrm{a}}$ values (see Table 1), and this probably accounts for the similar $\mathrm{pH}$-dependent profiles of both substrates.

The foregoing conclusions that only the neutral forms of xanthine and 1-methylxanthine are substrates of xanthine oxidase are at variance with a much earlier report by Bergmann and Levene (1976) on the relative rates of oxidation of a series of purines and thiopurines by milk xanthine oxidase. The objective was to obtain information about the "active" structures recognized by the enzyme, based in part on the arbitrary assumption of binding of substrates in rare tautomeric forms. All reactions were conducted at the optimal $\mathrm{pH} 8$. It is, consequently, of interest that the relative $V_{\max }$ values for Hyp (108), xanthine (100) and 6-thioxanthine (57) are similar, as are their $K_{\mathrm{m}}$ values, 3.3, 5.2 and $4.6 \mu \mathrm{M}$, respectively. Since at $\mathrm{pH} 8$ the population of the anions of Hyp ( $\mathrm{p} K_{\mathrm{a}}$ about 9 ), xanthine ( $\mathrm{p} K_{\mathrm{a}}$ about 7.7) and 6-thioxanthine ( $\mathrm{p} K_{\mathrm{a}}$ about 6.2$)$ are about $10 \%, 60 \%$, and $>95 \%$, respectively, it would appear that the enzyme effectively accepts both the neutral and monoanionic forms as substrates. These findings would have been more convincing if reaction rates had been followed as a function of $\mathrm{pH}$.

\section{PURINE NUCLEOSIDE PHOSPHORYLASES (PNP)}

These ubiquitous enzymes catalyze the cleavage (phosphorolysis) of the glycosidic bond of purine ribo- and 2'-deoxyribo-nucleosides in the presence of inorganic phosphate $\left(\mathrm{P}_{\mathrm{i}}\right)$, a reaction reversible with natural and many synthetic substrates, as follows:

$\beta$-nucleoside $+\mathrm{P}_{\mathrm{i}}$

purine base +

$\alpha$-D-ribose-1-phosphate

In intact cells, phosphorolysis is the predominant reaction, due to coupling with guanase and xanthine oxidase, leading to stepwise formation of xanthine (Xan) and, finally, urate (Bzowska et al., 2000). PNP is one of the major enzymes operating in the so-called purine salvage pathway, whereby purines liberated by phosphorolysis are converted by phosphoribosyltransferases (HGPRTase) to the corresponding nucleoside 5'-phosphates (see Section 13).

Replacement of $\mathrm{P}_{\mathrm{i}}$ by arsenate $(\mathrm{AsV})$ in the above reaction renders the reaction non-reversible, as follows:

$\beta$-nucleoside + arsenate

PNP

purine base $+\alpha$-D-ribose-1-arsenate

$\mathrm{H}_{2} \mathrm{O}$ ribose + arsenate,

due to the high instability of ribose-1-arsenate. Arsenolysis is frequently employed in studies on the reaction mechanisms of PNPs (e.g. Kline \& Schramm, 1993). But it has very recently been shown to also be of potential biological significance, as described below (Sec- 
tion 11.3). The enzyme has been isolated, purified and characterized from a wide range of mammalian and bacterial sources, revealing the existence of two major forms (Bzowska et al., 2000; Pugmire \& Ealick, 2002): (a) homotrimers, with a subunit molecular mass of about $31 \mathrm{kDa}$, which accept the 6-oxopurines Hyp and Gua, and their ribo- and 2 '-deoxyribo-nucleosides and, in some instances, Xan and (d)Xao (see below), but not 6-aminopurines; (b) homohexamers, with a subunit molecular mass of about $26 \mathrm{kDa}$, which accept the 6-amino Ade and (d)Ado in addition to the 6-oxopurines. The mammalian enzymes are usually trimers, whereas the bacterial ones are largely hexamers. Some reported exceptions to the foregoing are described by Bzowska et al. (2000) and Pugmire and Ealick (2002). In particular, the trimeric structure of the mammalian enzymes in the crystal has recently been confirmed for the human enzyme in solution by low-angle X-ray scattering (de Azevedo et al., 2003). By contrast, analytical ultracentrifugation suggests that the $E$. coli PNPI (which is a hexamer, a trimer of dimers, in the crystal) is, in solution, an equilibrium mixture of the hexamer and probably the dimer (see Bzowska et al., 2000), of obvious relevance to interpretation of kinetic data.

\subsection{Mammalian PNPs}

Numerous reports have described Xan and Xao as weak substrates of PNP of mammalian origin, but in all instances at only a single arbitrarily selected $\mathrm{pH}$, thus overlooking the presence of the monoanionic forms of these substrates at physiological pH. Friedkin (1952) long ago reported that phosphorolysis of dGuo at $\mathrm{pH} 7.4$ by a partially purified PNP from rat liver, known to contain guanase, led to appearance of the then unknown 2 -deoxyxanthosine (dXao), as shown by the reaction sequence in the next paragraph.

Phosphorolysis of Guo by the same enzyme led to appearance of Xao, subsequently also

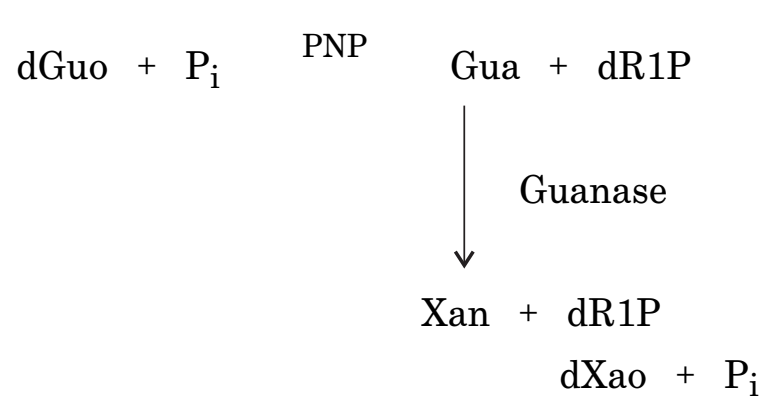

reported by Giorgelli et al. (1997), who were apparently unaware of the results of Friedkin. The dXao isolated by Friedkin (1952) was shown to be a substrate for phosphorolysis, at a rate about $2 \%$ that for dGuo at $\mathrm{pH} 7.4$.

The first comprehensive study of the substrate properties of Xan and Xao, with the mammalian enzymes (from human erythrocytes and calf spleen), over a broad range of pH, 3.5-8.5, is that of Stoychev et al. (2002). The optimum $\mathrm{pH}$ for these was found to be in the range 5-6, as compared to a range of 7-8 for Guo and Gua, and Ino and Hyp. This pH-dependence of the substrate properties of Xan and Xao pointed to both the neutral and anionic species as substrates, but with a very marked preference for the neutral forms.

Both the neutral and monoanionic forms of Xao were very poor inhibitors of phosphorolysis of Guo by human PNP, as was also Xan. In striking contrast, Gua was an excellent competitive inhibitor of phosphorolysis of Xao with a $K_{\mathrm{i}}$ about $2 \mu \mathrm{M}$. Furthermore, Xan was a good inhibitor of the reverse reaction with Hyp ( $\mathrm{IC}_{50}$ about $20 \mu \mathrm{M}$ ) (Stoycker et al., 2000), consistent with the finding of Krenitsky et al. (1968) that the reverse reaction for Hyp with human PNP is inhibited by Xan with a $K_{\mathrm{i}}$ about $40 \mu \mathrm{M}$.

\subsection{E. coli PNPII (Xao phosphorylase, Ino-Xao phosphorylase)}

In many instances, particularly microorganisms, there is more than one PNP, with different specificities (see Bzowska et al., 2000). 
Most interesting in this respect is $E$. coli, the PNP of which, referred to as PNPI, a hexameric product of the deoD gene, accepts as substrates the 6-oxo Gua and Hyp, and the 6-amino Ade, and their nucleosides. Koszalka et al. (1988) claimed that an apparently homogeneous PNPI from $E$. coli slowly cleaves Xao with a $V_{\max }$ about $4 \%$ that for Ino at neutral $\mathrm{pH}$. However, our homogeneous preparation of PNPI (by affinity chromatography) proved to be totally inactive $v$ Xao in the forward reaction, as well as Xan in the reverse synthetic reaction, over a broad $\mathrm{pH}$ range (Stoychev et $a l .$, 2002).

Cultivation of $E$. coli in the presence of Xao (but no other nucleoside) leads to appearance of a second hexameric PNP, referred to as Xao phosphorylase, a product of the $x a p A$ gene, the substrates of which include the 6-oxo Hyp, Gua and Xan and their nucleosides, with a preference for Xan and Xao, but not the 6-amino Ade and Ado (Hammer-Jespersen et al., 1980; Bezirjian et al., 1986). Koszalka et al. (1988) named this enzyme Ino-Guo phosphorylase. We consider it more appropriate to refer to it as PNPII.

The Swiss-Prot database refers to PNPII as inosine-xanthosine (Ino-Xao) phosphorylase. Its sequence bears no similarity to that of $E$. coli PNPI, for which Xan and Xao are not substrates (see above), but is similar to that of mammalian PNPs (Bzowska et al., 2000). But, notwithstanding its sequence similarity to mammalian PNPs (Seeger et al., 1995) which are trimers, PNPII has been shown to be a hexamer, although two groups have reported that gel filtration reveals the presence of a second minor peak identified as an active trimer (Hammer-Jesperson et al., 1980; Bezirjian et al., 1986). We, and others (G. Dandanell, personal communication), find that an apparently homogeneous PNPII exhibits only a single active peak identified as a hexamer.

In contrast to calf and human PNP, for which Xao is a weaker substrate than Guo (Stoychev et al., 2002), the pH-dependence of the apparent $V_{\max }$ values for Guo and Xao with PNPII (our unpublished data) show that both are comparable substrates, with a shift of the $\mathrm{pH}$ profile towards acidic $\mathrm{pH}$ for both Xao phosphorolysis and the reverse reaction with Xan. Furthermore, $V_{\max } / K_{\mathrm{m}}$ values for Guo and Xao with PNPII at pH 7 (Koszalka et $a l ., 1988$ ) are comparable, but the optimal $\mathrm{pH}$ range for enzyme activity is narrower for PNPII (Bezirjian et al., 1986) than for mammalian PNPs (Stoychev et al., 2002).

Xao $\left(\mathrm{p} K_{\mathrm{a}}\right.$ 5.7) is an excellent substrate for PNPII, and a moderate one for mammalian PNPs (Stoychev et al., 2002) in the $\mathrm{pH}$ range $7-8$, where it exists almost exclusively in the monoanionic form. By contrast, substrate activities of Guo and Ino are markedly reduced at $\mathrm{pH}>\mathrm{p} K_{\mathrm{a}}$. Bearing in mind that the active site of PNPII is similar to that of mammalian PNPs, with an Asn residue interacting with the N(7) and $\mathrm{O}^{6}$, and the Glu carboxylate hydrogen bonding to the $\mathrm{N}(1)-\mathrm{H}$, dissociation of the purine $\mathrm{N}(1)-\mathrm{H}$ in Guo and Ino leads to electrostatic repulsion with the negative charge of the Glu carboxylate, resulting in lack of substrate activity. With Xao, for which dissociation occurs at the N(3)-H (Section 3), its monoanionic form, a 6-oxopurine, is capable of interacting with the active site, and is in fact a good substrate.

\subsection{PNP and arsenate reductase}

Although not directly pertinent to the subject of this review, the following is worthy of note. The ubiquity of arsenic in the environment, and its associated highly deleterious effects on health, has prompted extensive studies on the biochemistry and toxicology of inorganic arsenic. Inorganic arsenate (AsV) and arsenite (AsIII) are present in carcinogenic concentrations in the drinking water of millions of people world-wide, and has led to the evolution of arsenic defense mechanisms in all organisms from $E$. coli to humans. Three families of arsenate reductase enzymes have now been extensively charac- 
terized in prokaryotes and yeast; but, to date, no mammalian counterparts of these have as yet been unequivocally identified (see Rosen, 2002).

Recently Radabaugh et al. (2002) reported a putative enzyme activity in human liver that led to reduction of arsenate to the more toxic arsenite, initially referred to as arsenate reductase. The activity was identified as PNP which, in the presence of a nucleoside, arsenate and a thiol (the naturally occurring dihydrolipoic acid, DHLP), led to the following reaction sequence:

$$
\begin{aligned}
& \beta \text {-nucleoside }+ \text { arsenate PNP } \\
& \text { purine base }+ \text { ribose-1-arsenate thiol } \\
& \text { arsenite }+ \text { ribose }+ \text { oxidized thiol }
\end{aligned}
$$

The proposal that this reaction may be of physiological importance in vivo is belied by the fact that cellular levels of DHLP are only in the micromolar range (see Nemeti et al., 2003). Waalkes and Liu (2002) have proposed that PNP may be a fortuitous intracellular arsenate reductase. From the reaction sequence described above, it appears that PNP is not a priori an arsenate reductase; it simply releases the highly labile ribose-1-arsenate which reacts non-enzymatically with an appropriate thiol to reduce liberated toxic arsenate to the more toxic arsenite. Further research is required to clarify the mechanism of the in vitro PNP-catalyzed reduction of As (V) to As (III), and its possible in vivo role.

\section{XANTHINE NUCLEOTIDE- SELECTIVE G PROTEINS}

GTP-binding proteins ( $\mathrm{G}$ proteins possessing GTPase activity), which are heterotrimeric $(\alpha \beta \gamma)$ structures, mediate transmembrane signaling transfer between receptors and effectors. The large superfamily of $G$ proteins includes also monomeric small $G$ proteins, such as Ras, Ran and Rab. Activated receptor promotes dissociation of GDP from $\mathrm{G} \alpha$, the rate-limiting step of the $\mathrm{G}$ protein cycle, followed by receptor-catalyzed binding of GTP to G $\alpha$. This induces the active conformation of the $\mathrm{G}$ protein, leading to dissociation of the heterotrimer to G $\alpha$-GTP and the $\beta \gamma$ complex, both of which are capable of modulating effector enzymes and ion channels. $\mathrm{G} \alpha$ possesses GTPase activity, which hydrolyzes GTP to GDP, thereby deactivating the G protein, following which G $\alpha$-GDP and $\beta \gamma$ reassociate to complete the G-protein cycle. A single receptor can activate more than one type of heterotrimer, while activated $\mathrm{G} \alpha$, and the $\beta \gamma$ subunit, can interact with multiple effectors. Moreover, cross-talk between different G protein-regulated pathways further contributes to the complexity of these networks (Neer, 1995).

One approach widely adopted to analysis of this complex network is to specifically activate a selected $\mathrm{G} \alpha$ protein in vivo to discern its function without interference from other G proteins, e.g. by switching, by means of mutation(s), its specificity from Gua nucleotides to one with another base moiety, the most widely preferred base being Xan. Although $\mathrm{XMP}$ is an intermediate in the biosynthesis of GMP from IMP (Section 14), the steady-state intracellular concentrations of XDP and XTP are very low. However, with the use of permeabilized cells, to allow uptake of XDP or XTP, it appears feasible to specifically activate the mutant protein ( $\mathrm{Yu}$ et al., 1997). Availability of an array of xanthine-nucleotide $\mathrm{G} \alpha$ proteins should therefore complement gene knockout and other approaches to delineate the function of an individual $\mathrm{G} \alpha$ protein in intact cell systems (Gille et al., 2003), recently extensively reviewed by Gille and Seifert (2004).

$\mathrm{G} \alpha$ consists of the ras-like domain, structurally similar to small GTP-binding proteins, and the $\alpha$-helical domain unique to $\mathrm{G} \alpha$, both embedding the nucleotide-binding pocket. Particularly important for guanine selectivity 
is an aspartate residue, belonging to the NKXD motif, highly conserved among small GTP-binding proteins and $\mathrm{G} \alpha$. Exchange of this aspartate for asparagine (Asp/Asn mutation) in small GTP-binding proteins was found to switch base selectivity from Gua to Xan, and such mutants have been successfully employed to study the properties of a given specific small GTP-binding protein in complex systems containing multiple GTP-binding proteins (Yanachkov et al., 1997).

Similar applications may be envisaged for $\mathrm{G}$ proteins, but, unexpectedly, Asp/Asn mutants of these were found to be inactive. However, additional exchange of a conserved glutamine for leucine, resulting in enhanced GDP affinity, which was found to be critical for functional expression of xanthine nucleotide-selective $\mathrm{G}$ protein mutants, led to the desired active $\mathrm{G} \alpha$ with xanthine nucleotide specificity (Yu et al., 2000; see Gille et al., 2003).

Clearly relevant to the foregoing is the mode of binding of XTP by a mutant $\mathrm{G}$ protein, bearing in mind that, at physiological $\mathrm{pH}$, the xanthine ring of XTP is > 95\% in the monoanionic form. The crystal structures of the $\alpha$-subunits of transducin and Gi both exhibit nearly identical binding pockets for the Gua nucleotide, similar to that in the crystal structures of Ras and EF-Tu. One of the conserved features is the interaction between a specific $\mathrm{G} \alpha$ amino-acid residue and the guanine ring, viz. hydrogen bonds from the side-chain carboxyl of a conserved aspartic acid (Asp-268 in transducin) to the ring $\mathrm{N}(1)$ and the $\mathrm{C}(2)-\mathrm{NH}_{2}$ of the guanine ring (Scheme 7a). Asp-268 of transducin belongs to the conserved motif, NKXD, found in all members of the GTPase superfamily, and it has been shown that characteristic hydrogen bonds formed with the Asp residue determines the specificity of nucleotide binding in other GTP-binding proteins, e.g. Ras and EF-Tu. Mutation of Asp to Asn at this position in other GTP-binding proteins results in active proteins regulated by xanthine, but not guanine, nucleotides (see Gille \& Seifert, 2004).

It is generally assumed that the mode of binding of XTP in the Asp mutants is via hydrogen bonding of the carboxamide side-chain of asparagine to the ring $\mathrm{N}(1)$ and the $\mathrm{C}(2)$ carbonyl of the xanthine ring (see Scheme 7b). This overlooks the fact that, at the $\mathrm{pH}$ of the reaction, the $\mathrm{N}(3)-\mathrm{H}$ of the xanthine ring is virtually fully ionized, such that an even stronger, ionic, hydrogen bond would occur, as shown in Scheme 7c. And, in fact, kinetic studies demonstrated that the a)

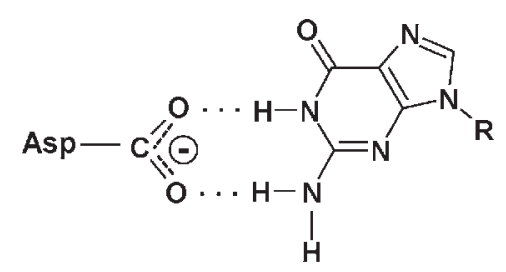

b)

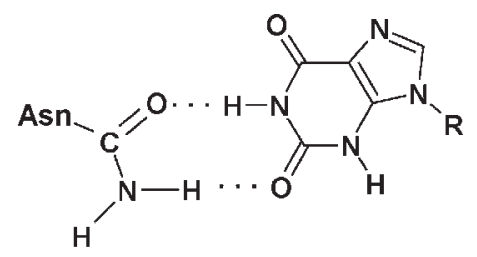

c)

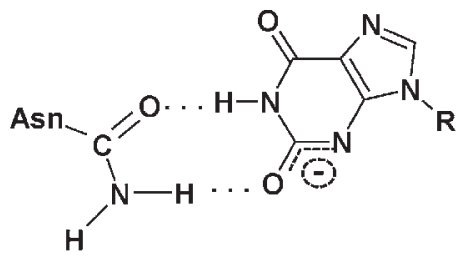

$\mathbf{R}=$ ribose 5-triphosphate

Scheme 7. Modes of binding of GTP and XTP by wild-type and mutant G proteins.

(a) Mode of binding of the guanine ring of GTP by an essential Asp residue (Asp268 in transducin) of a small GTP binding protein, as observed in several crystal structures; (b) proposed mode of binding of XTP when the Asp is replaced by Asn (see Yu et al., 1997); (c) alternative proposed mode of binding of XTP by the Asn mutant. 
D333N mutant of $E$. coli adenylosuccinate synthetase uses XTP as an energy source much more effectively than the wild type with GTP, ascribed to stronger bonding of the xanthine ring with the Asn333 of the mutant enzyme (Kang et al., 1994). It should, however, be noted that, with the wild type proteins, there is also an ionic hydrogen bond from the GTP amino group to an Asp carboxylate.

An interesting departure from the foregoing is the GTP-binding protein of the chloroplast outer envelope membrane, Arabidopsis Toc33, which was found to bind GTP, GDP and XTP (but not ATP) with similar efficiencies. D217N and D219N mutations within the nucleotide-binding domain did not affect nucleotide specificity or GTPase activity, nor Toc33 functionality in vivo (Aronsson et al., 2003). The unusual nucleotide-binding properties of this protein remain to be elucidated.

\section{PURINE PHOSPHORIBOSYL- TRANSFERASES (PRTases)}

Purine phosphoribosyltransferases (PRTases), enzymes active in the purine salvage pathway, catalyse the $\mathrm{Mg}^{2+}$-dependent reversible transfer of the 5-phosphoribosyl moiety of $\alpha$-D-5-phosphoribosyl-1-pyrophosphate (PR$\mathrm{PP})$ to N(9) of a purine base, yielding purine nucleotide and inorganic pyrophosphate:

$$
\text { Base + PRPP Mononucleotide }+\mathrm{PP}_{\mathrm{i}}
$$

Free living organisms can parallely synthesize purine nucleotides via de novo pathways, but protozoan parasites lack the enzymes for these routes, so that their salvage enzymes have long been considered as chemotherapeutic targets for parasitic diseases (Wang, 1984; el Kouni, 2003).

In humans, the main substrates of these enzymes are the 6-oxopurines Gua and Hyp for hypoxanthine-guanine phosphoribosyltransferase (HGPRTase) and the 6-aminopurine
Ade for adenine phosphoribosyltransferase (APRTase). The crystal structures of PRTases specific for Hyp and Gua exhibit an interaction between the $\mathrm{O}^{6}$ and a conserved, positively charged lysine (Lys165 in the human enzyme), thereby discriminating against 6-amino purines (Eads et al., 1994).

The 6-oxopurine Xan is salvaged by human HGPRTase at an extremely low level, and is converted to uric acid and excreted. By contrast, some bacteria and, especially, parasitic protozoa, possess PRTases with an elevated preference for Xan relative to Gua, and even so-called xanthine phosphoribosyltransferases (XPRTases) which preferentially catalyse the salvage of Xan and, inefficiently, Gua and Hyp (Craig \& Eakin, 2000; el Kouni, 2003), hence attractive targets for chemotherapy.

X-Ray structures of enzymes that accept Xan, when compared with those of the HGPRT class (Somoza et al., 1996; Shi et al., 1999a; 1999b; Vos et al., 1998; Héroux et al., 1999a; 1999b), in efforts to determine how an enzyme discriminates between the $\mathrm{C}(2)-\mathrm{NH}_{2}$ in Gua and the $\mathrm{C}(2)=\mathrm{O}$ in Xan, reveal that there is no common mechanism for binding of Xan. Whereas the modes of binding of Hyp and Gua in the forward reaction, and IMP and GMP in the reverse reaction, have been reasonably well assigned, the situation is much less clear for the modes of binding of Xan and XMP (Vos et al., 1997). The efficient use of Xan by some PRTases is also dependent on secondary structural features, e.g. a chimeric human HGPRTase, in which about $50 \mathrm{~N}$-terminal residues distal to the active site were replaced with the corresponding segment from $P$. falciparum HGXPRTase, exhibited enhanced specificity for Xan (Subbayya et al., 2000).

Crystallography, and kinetic experiments, have usually been performed at $\mathrm{pH}$ about 7 to 9 , where Xan $\left(\mathrm{p} K_{\mathrm{a}} 7.7\right)$ is a mixture of neutral and monoanionic forms, and the Xan ring of XMP ( $\mathrm{pKa}$ about 5.7) is predominantly, or even exclusively, an anion. But the possible 
involvement of these anionic forms, if at all, as substrates and/or as inhibitors, has been totally ignored. Moreover, at the resolutions hitherto attained, X-ray diffraction is unable to distinguish between a $\mathrm{C}(2)=\mathrm{O}$ and a $\mathrm{C}(2)-\mathrm{O}^{-}$, notwithstanding that the latter is a better acceptor. It would be helpful, in this context, to examine the $\mathrm{pH}$-dependence of the substrate properties of Xan and Gua, and their mutual competition, with an enzyme that utilizes both substrates. Such $\mathrm{pH}$-dependencies have been reported for enzymes that utilize Gua and Hyp (see below).

Molecular dynamics simulations were applied to this problem by Pitera et al. (1999) in attempts to explain the ability of the protozoan parasite Tritrichomonas foetus HGXPRTase to accept xanthine as a substrate, as against the human HGPRTase, which has a 100-fold lower affinity for xanthine relative to Gua and Hyp. The two enzymes exhibit only about $30 \%$ sequence identity. Their active sites, however, are very similar in structure, but do not explain why only the parasite enzyme recognizes xanthine and XMP. Calculations were based on splitting the nucleotides GMP and XMP into two parts, the base + sugar (treated as a single neutral species), and the phosphate group, taken as a singly charged anion. The nucleotides GMP and XMP were therefore each considered as carrying a charge of -1 . Since the reactions occur at physiological $\mathrm{pH}$, both assumptions are open to question. The phosphate group, with a $\mathrm{p} K_{\mathrm{a}} \approx 6.7$, would be predominantly a dianion under these conditions. As concerns the base in the case of XMP, the authors erroneously "considered only the 2-oxo tautomer, as enolic tautomers of the nucleobases are rarely populated in solution”, hence ignoring the fact that the xanthine ring in XMP is an anion under these conditions. Nonetheless, calculations led to excellent predictive findings, including the design of two active mutants. One conceivable, but rather unusual, interpretation is that the enzyme binds only the neutral form, and that the anionic species is totally inert.

Relevant to the foregoing are reports on substrate properties of the monoanion of Hyp, which binds to, and is a substrate of, T. crusi HGPRTase (Canyuk et al., 2001), although in this case monoanion formation $\left(\mathrm{p} K_{\mathrm{a}} 8.9\right)$ results from dissociation of the $\mathrm{N}(1)-\mathrm{H}$, with a negative charge at $\mathrm{O}^{6}$, and not of $\mathrm{N}(3)-\mathrm{H}$, with a charge at $\mathrm{O}^{2}$. The rates of IMP and GMP formation revealed an increase of HGPRTase activity at alkaline $\mathrm{pH}$, with a maximum or plateau at about $\mathrm{pH} 10$ (Olsen \& Milman, 1974; Johnson \& Nash, 1983; Xu \& Grubmeyer, 1998; Canyuk et al., 2001). This reflects the ionic state, not only of the enzyme side chains, but also of the purine substrate, but not of the cofactor PRPP (Canyuk et al., 2001). Increasing reaction rates with Hyp at $\mathrm{pH}>8$ were displayed also by three, weakly active, T. crusi HGPRTase mutants which possessed chemically different, non-ionizable side-chains at position 137, in place of Asp, a residue previously proposed as a general catalytic acid/base (Xu \& Grubmeyer, 1998), but subsequently questioned by Canyuk et al. (2001). This common characteristic of the $T$. crusi HGPRTase mutants suggests alkaline dissociation of Hyp rather than that of an enzyme residue (Canyuk et al., 2001), in line with an earlier report that Chinese hamster HPRTase utilizes the monoanion of Hyp (Olsen \& Milman, 1974).

Gua and Hyp PRTase activities in extracts of the archeabacterium Metanococcus voltae have been characterized by Bowen et al. (1996). These activities, both optimal at $\mathrm{pH} 9$, were not inhibited by Xan, nor by a variety of other purine base analogues, with the exception of 8-azaGua and 8-azaHyp (which were not substrates, and were bactericidal) and 2-thioxanthine. The latter is of particular interest, in that it inhibited only the Hyp, but not the Gua, PRTase activity, and, furthermore, did not inhibit growth of the organism, suggesting that it is a substrate, although not 
shown directly. Moreover, since its $\mathrm{p} K_{\mathrm{a}}$ is 5.9 (Stoychev et al., 2002), and reactions were conducted at $\mathrm{pH} 8$, it would appear that its monoanion may be the inhibitor, by virtue of its being a substrate. The possible substrate properties of 2-thioxanthine warrant further examination, but bearing in mind that the putative product, 2-thio-XMP, is hitherto unknown, hence not characterized. The inhibitory properties of 8-azaGua and 8-azaHyp are intriguing in that, unlike the parent Gua and Hyp, they undergo dissociation by loss of a proton from the triazole ring and, furthermore, with a $\mathrm{p} K_{\mathrm{a}} \approx 6.5$ (Wierzchowski et al., 1996), hence are exclusively monoanions at $\mathrm{pH} \mathrm{9,} \mathrm{but} \mathrm{with} \mathrm{the} \mathrm{pyrimidine} \mathrm{rings} \mathrm{identical}$ to those of Gua and Hyp, respectively, which may account for their ability to bind to, and inhibit, the enzymes.

\section{IMP DEHYDROGENASE AND GMP SYNTHETASE}

IMP dehydrogenase catalyzes the $\mathrm{NAD}^{+}$-dependent oxidation reaction that converts IMP to XMP, the rate-limiting step in guanine nucleotide biosynthesis. The reaction, shown in Scheme 8, appears to follow a random-in ordered-out mechanism, where the IMP substrate and the cofactor $\mathrm{NAD}^{+}$bind to the active site of the enzyme, followed by nucleophilic attack at the C(2) of IMP by an active site cysteine (Cys331 in human type II IMP dehydrogenase) to form an E-IMP* covalent intermediate. Hydride transfer from this intermediate to $\mathrm{NAD}^{+}$leads to formation of the intermediate $\mathrm{E}_{-} \mathrm{IMP}_{\mathrm{ox}}$ and NADH. A water molecule in the active site then intervenes to hydrolyze this covalent intermediate to E-XMP, with dissociation of NADH from the active site, followed by release of XMP.

$\mathrm{XMP}$, in turn, is converted to GMP by GMP synthetase, with glutamine as donor of the amino group, and ATP as energy source, as follows:

$$
\begin{aligned}
& \mathrm{XMP}+\mathrm{ATP}+\mathrm{Gln}+\mathrm{Mg}^{2} \\
& \mathrm{GMP}+\mathrm{AMP}+\mathrm{Glu}+\mathrm{PP}_{\mathrm{i}}
\end{aligned}
$$

In an extensive study of the $\mathrm{pH}$-dependence of the mechanism of the IMP dehydrogenase

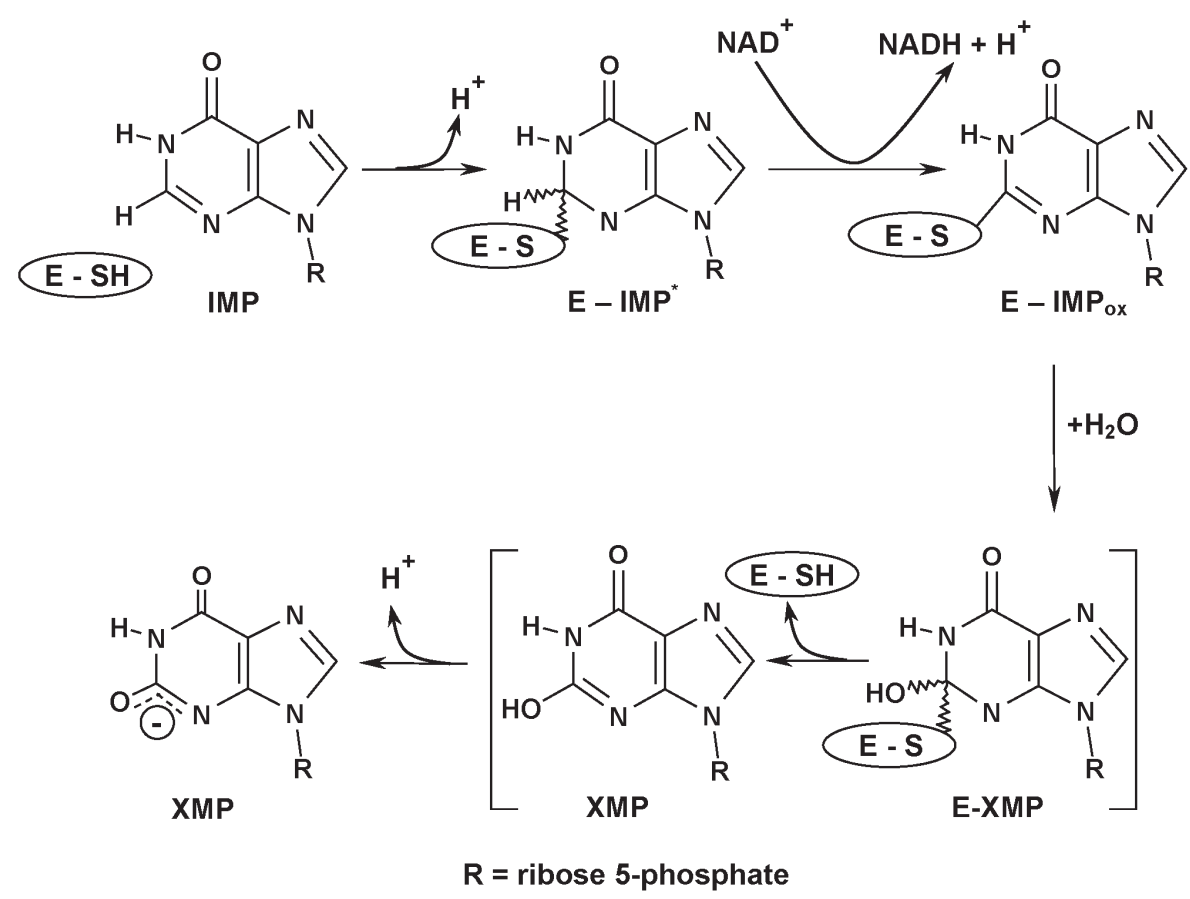

Scheme 8. NAD ${ }^{+}$-dependent oxidation of IMP to XMP catalyzed by IMP dehydrogenase. 
reaction, Markham et al. (1999) are the only authors to have recognized that, at physiological $\mathrm{pH}$, the final released product must be the C(2)-enolate of XMP. However, their suggestion that this is preceded by release of the C(2)-enol, which is then converted to the enolate, is, at best, problematical. The rate-limiting step is known to occur after hydride transfer, and could be hydrolysis of $\mathrm{E}-\mathrm{IMP}_{\text {ox }}$ or XMP release, the latter being favoured by demonstration of the absence of a deuterium isotope effect on $k_{\text {cat }}$.

As regards the subsequent conversion of released XMP to GMP by GMP synthetase, kinetic data, and positional isotope exchange indicated that the kinetic mechanism involves an ordered addition of substrates, with MgATP binding first, followed by XMP to form an adenylyl-XMP ester intermediate (von der Saal et al., 1985). The mechanism of this step, involving a nucleophilic attack by the C(2) oxygen of XMP at the $\alpha$-phosphate of ATP, with displacement of $\mathrm{PP}_{\mathrm{i}}$ (Scheme 9), clearly suggests that it is the monoanion of contrast to the known cytocidal effect of 6 -thiopurines on mammalian cells, the action of 6-thioxanthine on the parasite Toxoplasma gondii is uniquely parasitostatic. The compound proved to be a substrate of the parasite HGPRTase, leading to formation of 6-thioXMP, but not 6-thio-GMP. The absence of the latter product accounted for the lack of a parasitocidal effect, since incorporation of 6-thio-dGTP into nucleic acids is the mechanism for the lethal effect of 6-thiopurines on mammalian cells. Extracellular parasites that had accumulated a high concentration of 6-thio-XMP, as well as control parasites, efficiently used xanthine to make guanine nucleotides. This suggested that IMP dehydrogenase was being inhibited, while GMP synthetase was not, further confirmed by demonstrating directly in soluble extracts of T. gondii that 6-thio-XMP was an inhibitor of IMP dehydrogenase, with an $\mathrm{IC}_{50}$ about $100 \mu \mathrm{M}$. Inhibition was assumed to be competitive, in line with an earlier report that XMP is a competitive inhibitor of the human

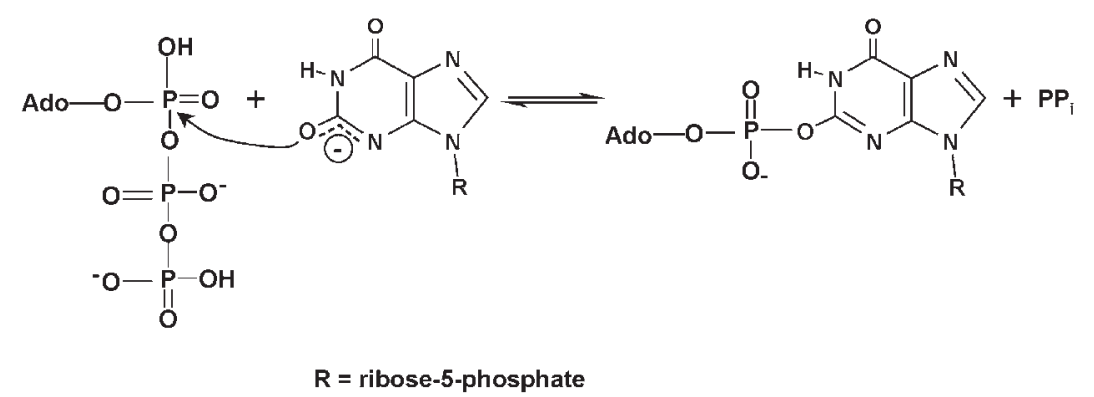

Scheme 9. Formation of an adenylyl-XMP ester intermediate, via nucleophilic attack by the C(2) oxygen of the monoanion of XMP, catalyzed by GMP synthetase.

$\mathrm{XMP}$ which is the substrate, a fact generally overlooked. Glutamine then donates its amino group to $\mathrm{C}(2)$ of the ester intermediate, followed by release of the adenylate, with formation of GMP. Both the foregoing enzymes, especially IMP dehydrogenase, have long been considered as favourable chemotherapeutic targets (Franchetti \& Grifantini, 1999; Pankiewicz, 2001).

Particularly intriguing was the observation of Pfefferkorn et al. (2001) that, in striking enzyme, with $K_{\mathrm{i}}$ 85-136 $\mu \mathrm{M}$ (Yamada et al., 1990). It follows that 6-thioxanthine is only parasitostatic because of inhibition of synthesis of guanine nucleotides.

\section{BIOSYNTHESIS OF CAFFEINE}

Caffeine, a member of a group of compounds known collectively as purine alkaloids, is present in high concentrations in cof- 
fee, tea and a few other plant species. The pathway(s) for its biosynthesis, especially in coffee and tea plants, has long been under investigation. This has been stimulated, in part, by the belief that ingestion of coffee may have adverse effects on health, with a consequent increased demand for decaffeinated
Scheme 10, which also displays two minor alternative routes for which there is some experimental evidence (see Ashihara \& Crozier, 2001; Mizuno et al., 2003; Uefuji et al., 2003). Note the absence of any reference to the ionic forms of the various substrates, discussed below.

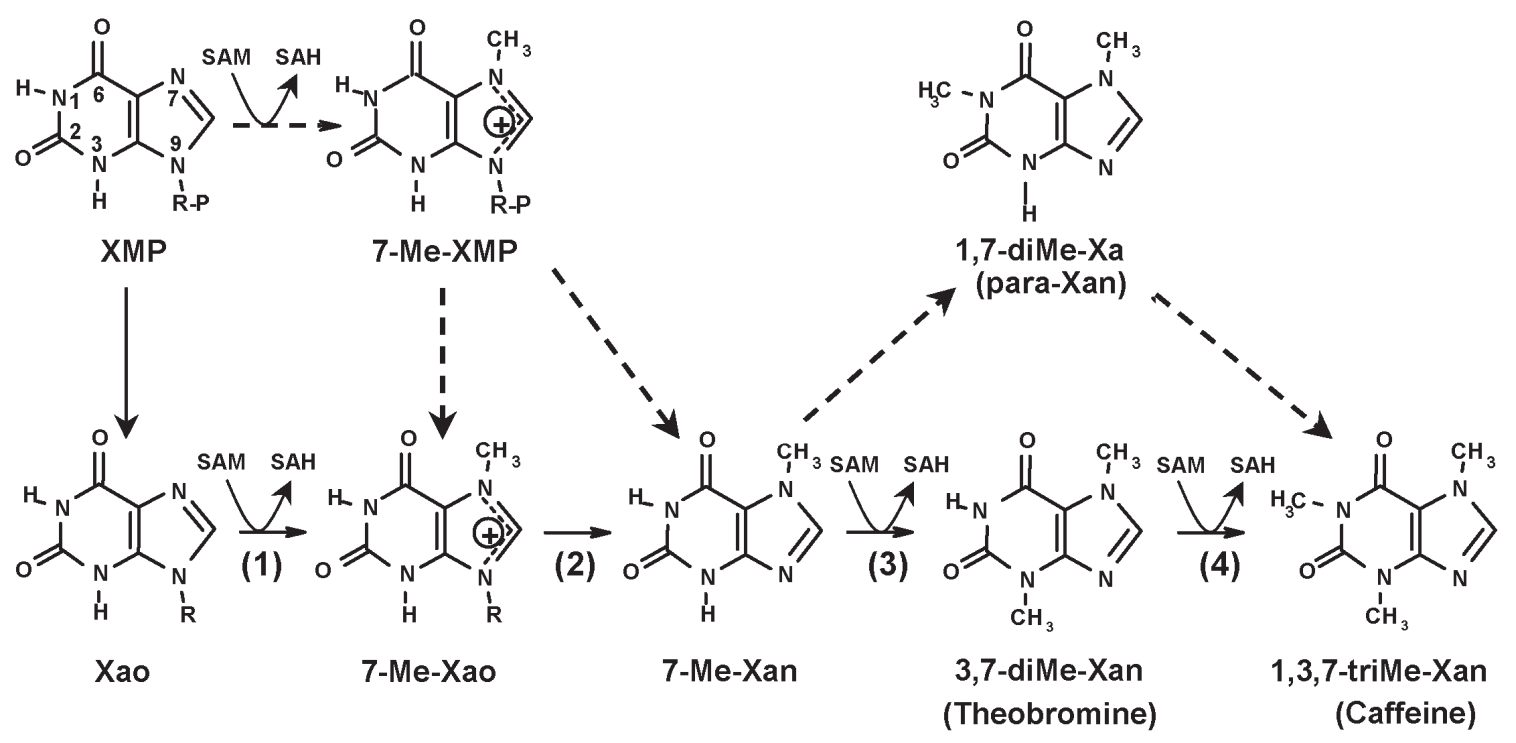

\section{$\mathbf{R}-\mathrm{P}=$ ribose 5-phosphate}

Scheme 10. Proposed pathways for biosynthesis of caffeine in coffee plants.

The major pathway, indicated by solid lines, is according to Mizuno et al. (2003) and Uefuji et al. (2003). Alternative routes in coffee plants and in tea plants (dashed lines) have been proposed by Schulthess et al. (1996), and Kato et $a l$. (1996). For the major pathway the enzymes involved, with $S$-adenosyl-L-methionine (SAM) as the methyl donor, are: (1) Xao N(7)-methyltransferase, (2) enzymatic cleavage of 7-Me-Xao to 7-Me-Xan (see text for details); (3) 7-Me-Xan N(3)-methyltransferase, (4) 3,7-diMe-Xan N(1)-methyltransferase. Note: see text for discussion of the actual structures of the substrates, and their relevance to the enzymes involved.

beverages, as well as the potential ecological role of caffeine. These aspects, and the impressive progress made during the past few years to elucidate the pathway for caffeine biosynthesis, have been recently reviewed by Ashihara and Crozier (2001), Ashihara and Suzuki (2004) and Kato and Mizuno (2004).

It is now generally accepted that the major pathway for synthesis of caffeine, starting from xanthosine (Xao), or its 5'-phosphate (XMP), proceeds via four steps, three of which are catalysed by $N$-methyltransferases, with $S$-adenosyl-L-methionine (SAM) as the methyl donor, as shown by steps $\mathbf{1}, \mathbf{3}$ and $\mathbf{4}$ in
The genes coding for the three $\mathrm{N}$-methyltransferases have recently been identified, cloned and expressed in E. coli, and the resultant recombinant enzymes purified and characterized, including their substrate specificities (Ogawa et al., 2001; Ashihara \& Crozier, 2001; Mizuno et al., 2003; Uefuji et al., 2003). Mizuno et al. (2003) have also reported the isolation, from Coffea arabica L., of a dual-functional caffeine synthase gene, which codes for a protein that catalyses both steps $\mathbf{3}$ and 4, similar to an enzyme previously isolated by the same authors from tea plants. As pointed out by Ashihara and Crozier (2001), 
such developments open up the possibility of producing long desired transgenic caffeine-free tea and coffee plants.

Uefuji et al. (2003) have successfully employed the three individual recombinant $\mathrm{N}$-methyltransferases, in combination with an E. coli extract to cleave 7-Me-Xao to 7-Me-Xan (step 2 in Scheme 10), to achieve the biosynthesis of caffeine, starting from $\mathrm{Xao}$, in vitro, in line with the proposed major pathway in vivo shown in Scheme 10, and in accord with that much earlier proposed in tea leaf extracts by Negishi et al. (1985).

In the experiments of Uefuji et al. (2003), it was assumed that step 2 , the cleavage of 7-Me-Xao to 7-Me-Xan, was due to a "non-specific" purine nucleoside phosphorylase (PNP) activity in the $E$. coli extract employed. But, as elsewhere shown, the PNP of wild-type $E$. coli, known as PNPI, does not cleave Xao (Stoychev et al., 2002). It is, however, not known whether it will cleave 7-Me-Xao. It would be useful to repeat the in vitro biosynthesis, with the use of purified $E$. coli PNPI in place of the bacterial extract. Alternatively, one could use PNPII of $E$ coli, an enzyme induced by cultivation of the bacteria in a medium containing Xao, and for which Xao is an excellent substrate (see Section 11.2). It is, of course, conceivable that the $E$. coli extract contains a nucleosidase (nucleoside hydrolase) which catalyses step 2. Hammer-Jespersen (1983) long ago excluded existence of a ribonucleoside hydrolase in $E$. coli. More recently Petersen \& Moller (2001) demonstrated the presence of three ribonucleoside hydrolases in $E$. coli, one of which, coded for by the rihC gene, is active against Xao, but the levels of expression of these genes were very low. By contrast, Negishi et al. (1985) reported the isolation, but only partial purification, of an enzyme from tea leaves, referred to as methylxanthine nucleosidase, which catalyses the hydrolysis of 7-Me-Xao to 7-Me-Xan. Similar activities have been reported by several observers in extracts of coffee plants (e.g. Roberts \& Waller,
1979; Schulthess et al., 1996). It would clearly be desirable to purify and characterize the specificity of these enzymes, in part because of the unusual structure of 7-Me-Xao at physiological $\mathrm{pH}$ (see below). Genes containing the characteristic fingerprint motifs for nucleoside hydrolases have been identified in a variety of organisms, including parasites and plants, a subject recently reviewed by Versees and Steyaert (2003). Surprisingly, neither nucleoside hydrolase activity, nor the associate encoding genes, have hitherto been detected in mammals, so that, e.g., parasitic nucleoside hydrolases should be excellent targets for chemotherapeutic intervention.

Reverting to the proposed scheme for biosynthesis of caffeine (Scheme 10), it is indeed astonishing that all the xanthine ring derivatives are implicitly assumed throughout the synthetic pathway to be uniquely in the neutral diketo form! We therefore redirect attention to Scheme 2 and Table 2 on the nature of the neutral and ionic forms of xanthine, methylated xanthines, and their nucleosides and nucleotides, leading to the following comments:

Step 1, catalysed by Xao N(7)-methyltransferase. The $\mathrm{pH}$ optimum for this reaction in vitro has been reported as 7 (Ashihara \& Crozier, 2001). At this $\mathrm{pH}$, the substrate Xao ( $\left.K_{\mathrm{a}} 5.7\right)$ exists about $95 \%$ as a monoanion, due to dissociation of the N(3)-H. The acid-base properties of the product, 7-Me-Xao, have not hitherto been characterized; but, by analogy with 7-Me-Ino and 7-Me-Guo, we would expect it to have a $\mathrm{p} K_{\mathrm{a}}$ at least $\leq 7$ for dissociation of the $\mathrm{N}(1)-\mathrm{H}$ or $\mathrm{N}(3)-\mathrm{H}$, and at $\mathrm{pH} 7$ would exist as an equilibrium mixture of the cation and one of these zwitterions.

However, in the absence of experimental data for 7-Me-Xao, a good evaluation of its structure is forthcoming from a study of Pfleiderer (1961) on the synthesis and properties of purine betaines, including that of xanthine. It was there shown that 7,9-diMeXan, which is a formal structural analogue of 
7-Me-Xao, exhibited an unusually low $\mathrm{p} K_{\mathrm{a}}$ of 3.18 for dissociation of the N(1)-H or N(3)-H. Additional methylation at $\mathrm{N}(1)$, so that only the $\mathrm{N}(3)-\mathrm{H}$ could dissociate, left this $\mathrm{p} K_{\mathrm{a}}$ unchanged, whereas methylation at N(3) led to a $\mathrm{p} K_{\mathrm{a}}$ of 7.0 for dissociation of the N(1)-H. It follows that, at physiological $\mathrm{pH}, 7,9$-diMe-Xan is uniquely a zwitterion with dissociation of the N(3)-H (Scheme 11). The same would ap-

\section{ALKYLXANTHINES: PHARMACOLOGICAL ASPECTS}

The marked pharmacological and toxicological effects of caffeine are known to be highly relevant to such phenomena as the blockade of G-protein-coupled adenosine receptors, inhibition of cyclic nucleotide phosphodiesterases, sensitization to calcium of the cyclic

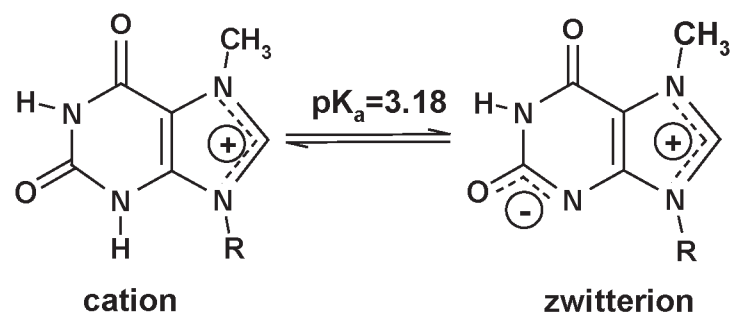

$\mathrm{R}=\mathrm{CH}_{3}$ or ribose

Scheme 11. The cationic and zwitterionic forms of 7,9-diMe-Xan, and, by analogy, of 7-Me-Xao.

Note the low $\mathrm{p} K_{\mathrm{a}}$ of 3.2 , so that these compounds are virtually zwitterions at physiological $\mathrm{pH}$.

ply to 7-Me-Xao, the zwitterion of which is the product of step $\mathbf{1}$, and the substrate of step $\mathbf{2}$ in Scheme 10. Step 3, catalysed by 7-Me-Xan $N(3)$-methyltransferase, with a very narrow $\mathrm{pH}$ optimum at $\mathrm{pH} 8.5$ in vitro (Ashihara \& Crozier, 2001). At this $\mathrm{pH}$, the substrate 7-Me-Xan ( $\mathrm{p} K_{\mathrm{a}}$ 8.35) exists as an approximate 1:1 mixture of the neutral and anionic forms. The product, 3,7-diMe-Xan ( $\mathrm{p} K_{\mathrm{a}}$ 9.9) exists predominantly, $>95 \%$, as the neutral diketo form, and is the substrate in the final step 4.

The in vitro synthesis of caffeine from Xao (steps 1 to $\mathbf{4}$ of Scheme 10) described by Uefuji et al. (2003) was performed at $\mathrm{pH} 8$. At this $\mathrm{pH}$, Xao is virtually $100 \%$ a monoanion, 7-Me-Xao $100 \%$ a zwitterion, 7-Me-Xan a 1:1 mixture of the neutral and monoanionic species, and 3,7-diMe-Xan in the neutral form. It is clearly desirable to establish to what extent the neutral and ionic species are involved in the various steps, e.g. by examining the $\mathrm{pH}$-dependence of each substrate with its appropriate enzyme, and/or the efficiency of the in vitro pathway as a function of $\mathrm{pH}$.
ADP ribose-modulated calcium-release channels associated with intracellular stores of calcium, inhibition of $\mathrm{GABA}_{\mathrm{A}}$ receptors. The effects of the natural methylxanthines, caffeine and theophylline, on the cardiovascular, respiratory, renal and nervous systems has thus led to the synthesis of an enormous number of alkylated xanthines with a view to obtaining more selective and potent agents, both as tools for elucidation of the mechanisms involved, and as potential chemotherapeutic agents, e.g. antiasthmatics, bronchodilators, cardiac stimulants, treatment of renal failure, etc., recently comprehensively reviewed by Daly (2000).

Most of the synthetic compounds hitherto reported are alkylated at both the ring $\mathrm{N}(1)$ and $\mathrm{N}(3)$, thus precluding their predominance as anions at physiological $\mathrm{pH}$ (see Table 1). Many of these are additionally alkylated at $\mathrm{N}(7)$ or N(9), hence exist only as the neutral species. There are, however, instances of mono- and di-N-alkyl analogues where this is not the case, and furthermore, the acid-base 
properties of which have been totally disregarded in structure-activity relationship (SAR) studies. We limit ourselves to several typical examples.

One such is a report by Foley et al. (2003a) on analogues of 3-alkyl-1,8-dibenzylxanthines which are good GTP-competitive inhibitors of phosphoenolpyruvate carboxykinase, which catalyzes the rate-limiting step in gluconeogenesis, inhibition of which would be expected to lead to a decrease in fasting blood glucose levels in diabetic patients. In this series of compounds, the imidazole ring of the neutral form is protonated. As a 1,3-dialkylxanthine, its $\mathrm{p} K_{\mathrm{a}}$ for dissociation of the imidazole proton would be in the vicinity of 9 (see Table 1), if we disregard the possible minor effects of the C(8)-benzyl substituent. It follows that, at physiological $\mathrm{pH}$, the predominant species should be the neutral form, consistent with the conclusion of the authors, on the basis of an SAR study, that the N(7)-H was essential for activity. This was further supported by the demonstration (Foley et al., $2003 \mathrm{~b}$ ) that, in the crystal structure of the enzyme with an inhibitor, the N(7)-H of the latter is a donor, via a water molecule, to Trp516 and Trp527 in the active site.

A very active field has been the development of adenosine receptor antagonists as pharmacological tools, and as potential drugs, exemplified by a recent study on a series of 1,8-disubstituted xanthines as potent and selective antagonists of the human $\mathrm{A}_{2 \mathrm{~B}}$ adenosine receptor (Hayallah et al., 2002), with potential therapeutic applications in asthma, type II diabetes and cystic fibrosis. These compounds, surprisingly, were found to be equipotent, or even more potent, at $\mathrm{A}_{2 \mathrm{~B}}$ receptors than 1,3,8-trisubstituted xanthines. The most selective was 1-propyl-8-p-sulfophenylxanthine, with a $K_{\mathrm{i}} \approx 50 \mathrm{nM}$ at the human $\mathrm{A}_{2 \mathrm{~B}}$ adenosine receptors, and an almost 200 -fold selectivity $v s$ the human $\mathrm{A}_{1}$ adenosine receptors. Two additional analogues exhibited $K_{\mathrm{i}}$ values at the $\mathrm{A}_{2 \mathrm{~B}}$ receptors as low as $1 \mathrm{nM}$, with an up to 100 -fold selectivity vs human $\mathrm{A}_{1}$, and > 400-fold selectivity vs human $A_{2 A}$ and $A_{3}$, receptors. These compounds were initially developed for use in elucidation of the function of the $\mathrm{A}_{2 \mathrm{~B}}$ receptor. However, as in all such studies, no consideration was given to the fact that all of them are formally analogues of 1-methylxanthine, with a $\mathrm{p} K_{\mathrm{a}}$ for dissociation of the $\mathrm{N}(3)-\mathrm{H}$ of 7.7 , hence with $\mathrm{a} \approx 1: 1$ population of the neutral and anionic species at physiological $\mathrm{pH}$, clearly relevant to their mode of binding, and use for delineation of receptor function. This also applies to an earlier study by Shamim et al. (1989) in which 1-methylxanthine was found to be relatively potent and selective for the human platelet $\mathrm{A}_{2}$ adenosine receptor, whereas 1-propyl-8-phenylxanthine proved to be a highly potent ( $K_{\mathrm{i}} 20-70 \mathrm{nM}$ ), albeit non-selective at both $\mathrm{A}_{1}$ and $\mathrm{A}_{2}$ receptors. It would, of course, be desirable to determine to what extent, if any, the $\mathrm{p} K_{\mathrm{a}}$ is affected by 1and 8-substituents other than a methyl, particularly when such substitutents bear a charge, e.g. analogues with the above-mentioned highly negatively charged 8-sulfophenyl moiety (which additionally affects ability to penetrate membranes). Yan and Muller (2004) demonstrated that a nitrophenyl ester of 1-propyl-8-p-sulfophenylxanthine, referred to above as a selective $A_{2 B}$ antagonist, undergoes cleavage of the nitrophenyl group by a rat liver homogenate, presumably enzymatically, suggesting potential use of the ester as a peroral prodrug. It would be of interest to determine the $\mathrm{p} K_{\mathrm{a}}$ of the $\mathrm{N}(3)-\mathrm{H}$ in this analogue prior to, and following, cleavage of the nitrophenyl moiety. In an earlier study, which included mono- and di-substituted xanthines, Muller et al. (1993) noted that analogues with a substituent on the ring N(9), e.g. 9-methylxanthine and 9-ethylxanthine, as well as 1,9-dimethylxanthine, were virtually inactive. This may also be ascribed, at least in part, to the fact that an N(9)-substituent lowers the $\mathrm{p} K_{\mathrm{a}}$ to about 6.3, so that these compounds are predominantly anions at physiological $\mathrm{pH}$. The observed inactivity of 7,9-dimethylxan- 
thine, on the other hand, is most likely related to its very low $\mathrm{p} K_{\mathrm{a}}$ of 3.2 , so that it is exclusively a zwitterions at $\mathrm{pH} \geq 6$ (see below).

The stimulatory effects of caffeine on skeletal, cardiac and smooth muscle are known to be due largely to increases in intracellular calcium, the putative target being a cyclic ADP-ribose-mediated ryanodine-sensitive calcium-release channel, where calcium increases the sensitivity of the channel to activation by $\mathrm{Ca}^{2+}$. Various alkylxanthine analogues have been employed in SAR studies on calcium-invoked calcium release through such channels, all of them largely empirical, and with no regard to the acid-base properties of the analogues employed. In one such investigation (Rousseau et al., 1988), using methylxanthines, four dimethylxanthines, 1,3-, 1,7-, 3,7- and 3,9- were found to be equally, or even more, effective than caffeine in enhancement of the $\mathrm{Ca}^{2+}$ efflux rate from the channels. But no attention was drawn to the fact that all four have a $\mathrm{p} K_{\mathrm{a}} \approx 8.6$ (see Table 1), so that their neutral forms predominate at physiological $\mathrm{pH}$. In striking contrast, 1,9-dimethylxanthine, with a $\mathrm{p} K_{\mathrm{a}} \approx 6.3$ (see Table 1), due to dissociation of the N(3)-H, and hence predominantly a monoanion at physiological $\mathrm{pH}$, was totally inactive. The authors also refer to earlier reports that 7,9-dimethylxanthine is equally inactive, but they were apparently unaware that this analogue is a purine betaine, with a positive charge on the imidazole ring, and, furthermore, with an unusually low $\mathrm{p} K_{\mathrm{a}} \approx 3.2$ for dissociation of the $\mathrm{N}(3)-\mathrm{H}$, and is therefore exclusively a zwitterion at physiological $\mathrm{pH}$ (see Section 15).

\section{7-METHYLXANTHOSINE-5'- DIPHOSPHATE ( $\left.{ }^{7} \mathrm{XDP}\right)$ AND mRNA CAP}

Nuclear transcribed mRNA possesses a 5 '-terminal “cap”, $\mathrm{m}^{7} \mathrm{GpppN}$, in which 7-methylguanosine- $5^{\prime}$-triphosphate $\left(\mathrm{m}^{7} \mathrm{GTP}\right)$ is linked to the $5^{\prime}$-position of the first nucleoside N. This cap structure is required for several functions, including optimal mRNA translation, which is mediated by the protein initiation factor $4 \mathrm{E}$ (eIF4E). Consequently the mode of binding of the cap with eIF4E is of some interest, the more so in that $\mathrm{m}^{7}$ Guo at physiological pH exists as a $1: 1$ equilibrium mixture of the cation, with a positive charge on the imidazole ring, and the zwitterion, due to dissociation of the ring $\mathrm{N}(1)-\mathrm{H}\left(\mathrm{p} K_{\mathrm{a}} \approx 7.2\right)$.

In the crystal structures of eIF4E complexed with $\mathrm{m}^{7} \mathrm{GDP}$ or $\mathrm{m}^{7} \mathrm{GpppG}$, the 7-methylguanine moiety is sandwiched between Trp56 and Trp102, the N(1)-H and the $\mathrm{N}^{2} \mathrm{H}$ are hydrogen bonded to the Glu103 carboxylate, while the $\mathrm{O}^{6}$ accepts a hydrogen from the NH of the Trp102 backbone (Marcotrigiano et al., 1997; Niedzwiecka et al., 2002a). This implies that it is the cation which is bound by eIF4E. But, surprisingly, measurements in solution of the $\mathrm{pH}$-dependence of the association constant for binding displayed a broad plateau between $\mathrm{pH} 6.6$ and 7.6, with only a surprisingly slow decrease in affinity both below and above this $\mathrm{pH}$ range (Niedzwiecka et al., 2002a). However, subsequent measurements of the van't Hoff and calorimetric enthalpy values for binding pointed to the cation as the active form (Niedzwiecka et al., 2002b).

The foregoing directed our attention to a report by Shatkin and coworkers (Adams et al., 1978) on the inhibition of reovirus mRNA binding to wheat germ ribosomes at $\mathrm{pH} 7.6$ by $\mathrm{m}^{7} \mathrm{GDP}$ and some structurally related analogues, including $\mathrm{m}^{7} \mathrm{XDP}$. It was found that $\mathrm{m}^{7}$ IDP was only $50 \%$ as effective as $\mathrm{m}^{7} \mathrm{GDP}$, conceivably due in part to absence of the $\mathrm{NH}_{2}$ donor at $\mathrm{C}(2)$ of the hypoxanthine ring, thus reducing affinity. Moreover, the $\mathrm{p} K_{\mathrm{a}}$ for dissociation of the $\mathrm{N}(1)-\mathrm{H}$ of $\mathrm{m}^{7}$ IDP is at least 0.6 units below that for the N(1)-H of $\mathrm{m}^{7} \mathrm{GDP}$ (Kulikowska et al., 1986), so that, at $\mathrm{pH} 7.6$, $\mathrm{m}^{7}$ IDP exists to a much larger extent as the zwitterion, with the consequent absence of 
an N(1)-H for binding to the Glu103 carboxylate. Finally, $\mathrm{m}^{7} \mathrm{XDP}$ was found to exhibit only minimal inhibition, if at all. The $\mathrm{p} K_{\mathrm{a}}$ of the xanthine ring of $\mathrm{m}^{7} \mathrm{XDP}$ has not been reported, but its structural analogue, 7,9-dimethylxanthine, is highly acidic, with a $\mathrm{p} K_{\mathrm{a}} \approx 3.2$, for dissociation of the $\mathrm{N}(3)-\mathrm{H}$, so that at physiological $\mathrm{pH}$ it, and, by analogy, $\mathrm{m}^{7} \mathrm{XDP}$, would exist exclusively as the zwitterion, and, furthermore, with the N(1) protonated (see Section 15), hence capable of bonding to the Glu103 carboxylate. Nonetheless, the zwitterion proved essentially inactive, most likely due to electrostatic repulsion between the negatively charged $\mathrm{O}^{2}$ and the Glu103 carboxylate, hence in accord with the proposal that the cation of $\mathrm{m}^{7} \mathrm{GDP}$ is the active species.

\section{R E F E R E N C E S}

Adams BL, Morgan M, Muthukrishnan S, Hecht SM, Shatkin AJ. (1978) The effect of "cap" analogs on reovirus mRNA binding to wheat germ ribosomes. Evidence for enhancement of ribosomal binding via a preferred cap conformation. J Biol Chem.; 253: 2589-95.

Albert A, Brown D. (1954) Purine studies. Part I. Stability to acid and alkali. Solubility. Ionization. Comparison with pteridines. J Chem Soc.; 2060-71.

Arnott S, Chandrasekaran R, Day AW, Puigjaner LC, Watts L. (1981) Double-helical structures for polyxanthylic acid. $J \mathrm{Mol}$ Biol.; 149: 489-505.

Aronsson H, Combe J, Jarvis P. (2003) Unusual nucleotide-binding properties of the chloroplast protein import receptor, atToc33. FEBS Lett.; 544: 79-85.

Ashihara H, Crozier A. (2001) Caffeine: a well known but little mentioned compound in plant science. Trends Plant Sci.; 6: 407-13.

Ashihara H, Suzuki T. (2004) Distribution and biosynthesis of caffeine in plants. Front Biosci.; 9: 1864-76.
Bergmann F, Dickstein S. (1955) The relationship between spectral shifts and structural changes in uric acids and related compounds. J Am Chem Soc.; 77: 691-6.

Bergmann F, Levene L. (1976) Oxidation of N-methyl substituted hypoxanthines, xanthines, purine-6,8-diones and the corresponding 6-thiooxo derivatives by bovine milk xanthine oxidase. Biochim Biophys Acta.; 429: $672-88$.

Bessman MJ, Frick DN, O’Handley SF. (1996) The MutT proteins or "Nudix" hydrolases, a family of versatile, widely distributed, "housecleaning" enzymes. J Biol Chem.; 271: 25059-62.

Bezirjian KhO, Kocharian ShM, Akopyan ZhI. (1986) Isolation of a hexameric form of purine nucleoside phosphorylase II from $E$. coli. Comparative study of trimeric and hexameric forms of the enzyme. Biokhimia; 51: 1085-92.

Bowen TL, Lin WC, Whitman WB. (1996) Characterization of guanine and hypoxanthine phosphoribosyltransferases in Methanococcus voltae. J Bacteriol.; 178: 2521-6.

Brocklehurst K. (1994) A sound basis for pH-dependent kinetic studies on enzymes. Protein Eng.; 7: 291-9.

Bzowska A, Kulikowska E, Shugar D. (2000) Purine nucleoside phosphorylases: properties, functions, and clinical aspects.

Pharmacol Ther:; 88: 349-425.

Canyuk B, Focia PJ, Eakin AE. (2001) The role for an invariant aspartic acid in hypoxanthine phosphoribosyltransferases is examined using saturation mutagenesis, functional analysis, and X-ray crystallography. Biochemistry.; 40: 2754-65.

Caulfield JL, Wishnok JS, Tannenbaum SR. (1998) Nitric oxide induced deamination of cytosine and guanine in deoxynucleosides and oligonucleotides. $J$ Biol Chem.; 273: 12689-95.

Cavalieri L, Fox JJ, Stone A, Chang N. (1954) On the nature of xanthine and substituted 
xanthines in solution. $J$ Am Chem Soc.; 76: 1119-22.

Christensen JJ, Rytting JH, Izatt RM. (1970) Thermodynamic $\mathrm{pK}, \mathrm{H}^{\mathrm{o}}, \mathrm{S}^{\mathrm{o}}$, and $\mathrm{Cp}^{\mathrm{o}}$ values for proton dissociation from several purines and their nucleosides in aqueous solution. Biochemistry.; 9: 4907-13.

Chung JH, Back JH, Park YI, Han YS. (2001)

Biochemical characterization of a novel hypoxanthine/xanthine dNTP pyrophosphatase from Methanococcus jannaschii. Nucleic Acids Res.; 29: 3099-107.

Chung JH, Park H-Y, Lee JH, Jang Y. (2002) Identification of the dITP- and XTP-hydrolyzing protein from Escherichia coli. $J$ Biochem Mol Biol.; 35: 403-8.

Craig SP III, Eakin AE. (2000) Purine phosphoribosyltransferases. J Biol Chem.; 275: 20231-4

Daly JW. (2000) Alkylxanthines as research tools. J Auton Nerv Syst.; 31: 44-52.

Datta NS, Shewach DS, Hurley MC, Mitchell BS, Fox IH. (1989) Human T-lymphoblast deoxycytidine kinase: Purification and properties. Biochemistry.; 28: 114-23.

de Azevedo Jr WF, dos Santos GC, dos Santos DM, Olivieri JR, Canduri F, Silva RG, Basso LA, Renard G, da Fonseco IO, Mendes MA, Palma MS, Santos DS. (2003) Docking and small angle X-ray scattering studies of purine nucleoside phosphorylase. Biochem Biophys Res Commun.; 309: 923-8.

Eads JC, Scapin G, Xu Y, Grubmeyer C, Sacchettini JC. (1994) The crystal structure of human hypoxanthine-guanine phosphoribosyltransferase with bound GMP. Cell.; 78: 325-34.

el Kouni MH. (2003) Potential chemotherapeutic targets in the purine metabolism of parasites. Pharmacol Ther.; 99: 283-309.

Elgemeie GH. (2003) Thioguanine, mercaptopurine: their analogues and nucleosides as antimetabolites. Curr Pharm Des.; 9: 2627-42.
Eritja R, Horowitz DM, Walker PA, Ziehler-Martin JP, Boosalis MS, Goodman MF, Itakura K, Kaplan BE. (1986) Synthesis and properties of oligonucleotides containing 2 -deoxynebularine and 2 -deoxyxanthosine. Nucleic Acids Res.; 14: 8135-53.

Fikus M, Shugar D. (1969) Properties of poly-xanthylic acid and its reactions with potentially complementary homopolynucleotides. Acta Biochim Polon.; 16: 55-82.

Foley LH, Wang P, Dunten P, Ramsey G, Gubler M-L, Wertheimer SJ. (2003a) Modified 3-alkyl-1,8-dibenzylxanthines as GTP-competitive inhibitors of phosphoenolpyruvate carboxykinase. Bioorg Med Chem Lett.; 13: 3607-10.

Foley LH, Wang P, Dunten P, Ramsey G, Gubler M-L, Wertheimer SJ. (2003b) X-Ray structures of two xanthine inhibitors bound to PEPCK and N-3 modifications of substituted 1,8-dibenzylxanthines. Bioorg Med Chem Lett.; 13: 3871-34.

Franchetti P, Grifantini M. (1999) Nucleoside and non-nucleoside IMP dehydrogenase inhibitors as antitumour and antiviral agents. Curr Med Chem.; 6: 599-614.

Friedkin M. (1952) Enzymatic synthesis of deoxyxanthosine by the action of xanthosine phosphorylase in mammalian tissue. $J \mathrm{Am}$ Chem Soc.; 74: 112-5.

Geyer CR, Battersby TR, Benner SA. (2003) Nucleobase pairing in expanded WatsonCrick-like genetic information systems. Structure.; 11: 1485-98.

Gille A, Seifert R. (2004) Xanthine nucleotide-specific G-protein alpha-subunits: a novel approach for the analysis of G-protein-mediated signal transduction. Naunyn Schmiederbergs Arch Pharmacol.; 369: 141-50.

Gille A, Wenzel-Seifert K, Doughty MB, Seifert R. (2003) GDP affinity and order state of the catalytic site are critical for function of xanthine nucleotide-selective $\mathrm{G} \alpha_{\mathrm{S}}$ proteins. $J$ Biol Chem.; 278: 7822-8. 
Giorgelli F, Bottai C, Mascia L, Scolozzi C, Camici M, Ipata PL. (1997) Recycling of alpha-D-ribose 1-phosphate for nucleoside interconversion. Biochim Biophys Acta.; 1335: 6-22.

Hammer-Jespersen K. (1983) Nucleoside catabolism. In Metabolism of Nucleotides, Nucleosides and Nucleobases in Microorganisms. Munch-Petersen A. ed, pp 203-58. Academic Press, London.

Hammer-Jespersen K, Buxton RS, Hansen TD. (1980) A second purine nucleoside phosphorylase in Escherichia coli K-12. II. Properties of xanthosine phosphorylase and its induction by xanthosine. Mol Gen Genet.; 179: $341-8$.

Hayallah AM, Sandoval-Ramirez J, Reith U, Schobert U, Preiss B, Schumacher B, Daly JW, Muller CE. (2002) 1,8-Disubstituted xanthine derivatives: synthesis of potent A2B-selective adenosine receptor antagonists. J Med Chem.; 45: 1500-10.

He B, Quing H, Kow W. (2000)

Deoxyxanthosine in DNA is repaired by Escherichia coli endonuclease V. Mutat Res.; 459: 109-14.

Héroux A, White EL, Ross LJ, Borhani DW. (1999a) Crystal structures of the Toxoplasma gondii hypoxanthine-guanine phosphoribosyltransferase-GMP and -IMP complexes: comparison of purine binding interactions with the XMP complex. Biochemistry.; 38: 14485-94.

Héroux A, White EL, Ross LJ, Davis RL, Borhani DW. (1999b) Crystal structure of Toxoplasma gondii hypoxanthine-guanine phosphoribosyltransferase with XMP, pyrophosphate, and two $\mathrm{Mg}^{2+}$ ions bound: insights into the catalytic mechanism. Biochemistry.; 38: 14495-506.

Hille R. (1996) The mononuclear molybdenum enzymes. Chem Rev.; 96: 2757-816.

Hwang KY, Chung JH, Kim S-H, Han YS, Cho Y. (1999) Structure-based identification of a novel NTPase from Methanococcus jannaschii. Nat Struct Biol.; 6: 691-6.
Johnson GG, Nash SA. (1983)

Hypoxanthine-guanine phosphoribosyltransferase in human erythroid cells: Properties of the isozymes. Biochem Genetics.; 21: $213-26$.

Kamiya H, Shimizu M, Suzuki M, Inoue H, Ohtsuka E. (1992) Mutation induced by deoxyxanthosine in codon 12 of a synthetic c-Ha-ras gene. Nucleosides Nucleotides.; 11: 247-60.

Kang C, Sun N, Honzatko RB, Fromm HJ. (1994) Replacement of $\mathrm{Asp}^{333}$ with Asn by site-directed mutagenesis changes the substrate specificity of Escherichia coli adenylosuccinate synthetase from guanosine-5 -triphosphate to xanthosine-5 -triphosphate. J Biol Chem.; 269: 24046-9.

Kato M, Kanehara T, Shimizu H, Suzuki T, Gillies FM, Crozier A, Ashira H. (1996) Caffeine biosynthesis in young leaves of Camellia sinensis: In vitro studies on N-methyltransferase activity invloved in the conversion of xanthosine to caffeine. Physiol Plant.; 98: $629-36$.

Kato M, Mizuno K. (2004) Caffeine synthase and related methyltransferases in plants. Frontiers Biosci.; 9: 1833-42.

Kim JH, Ryan MG, Knaut H, Hille R. (1996) The reductive half-reaction of xanthine oxidase. The involvement of prototropic equilibria in the course of the catalytic sequence. J Biol Chem.; 271: 6771-80.

Kline PC, Schramm VL. (1993) Purine nucleoside phosphorylase. Catalytic mechanism and transition-state analysis of the arsenolysis reaction. Biochemistry.; 32: 13212-9.

Koszalka GW, Vanhooke J, Short SA, Hall WW. (1988) Purification and properties of inosine-guanosine phosphorylase from Escherichia coli K-12. J Bacteriol.; 170: 3493-8.

Krenitsky TA, Elion GB, Henderson AM, Hitchings GH. (1968) Inhibition of human purine nucleoside phosphorylase. Studies with intact erythrocytes and the purified enzyme. J Biol Chem.; 243: 4779-84. 
Kulikowska E, Bzowska A, Wierzchowski J, Shugar D. (1986) Properties of two unusual, and fluorescent substrates of purine nucleoside phosphorylase: 7-methylguanosine and 7-methylinosine. Biochim Biophys Acta.; 874: $355-63$.

Lesyng B, Marck C, Saenger W. (1984) The crystal structure of anhydrous xanthosine displays intramolecular $\mathrm{O}\left(2^{\prime}\right) \mathrm{H}-\mathrm{O}\left(3^{\prime}\right) \mathrm{H}$ hydrogen bond. $Z$ Naturforsch.; 39: 720-4.

Liaw Y-C, Chern J-W, Lin G-S, Wang AH-J. (1992) Unusual conformational flexibility in $\mathrm{N}^{1}$-substituted uncommon purine nucleosides. Crystal structure of 1-allyl-isoguanosine and 1-allyl-xanthosine. FEBS Lett.; 297: 4-8.

Lichtenberg D, Bergmann F, Neiman Z. (1971) Tautomeric forms and ionization processes in xanthine and its N-methyl derivatives. $J$ Chem Soc (C).; 1676-82.

Lichtenberg D, Bergmann F, Neiman Z. (1972) Tautomerism and ionization processes in 6-thioxanthine and its N-methyl derivatives. $J$ Chem Soc Perkin II.; pp 1676-81.

Lin S, McLennan AG, Ying K, Wang Z, Gu S, Jin $\mathrm{H}, \mathrm{Wu} \mathrm{C}$, Liu W, Yuan Y, Tang R, Xie Y, Mao Y. (2001) Cloning, expression and characterization of a human inosine triphosphate pyrophosphatase encoded by the ITPA gene. J Biol Chem.; 276: 18695-701.

Lindahl T. (1993) Instability and decay of the primary structure of DNA. Nature.; 362: $709-15$.

Marcotrigiano J, Gingras AC, Sonnenberg N, Burley SK. (1997) Cocrystal structure of the messenger RNA 5 cap-binding protein (eIF4E) bound to 7-methyl-GDP. Cell.; 89: 951-61.

Markham GD, Bock CL, Schalk-Hihi C. (1999) Acid-base catalysis in the chemical mechanism of inosine monophosphate dehydrogenase. Biochemistry.; 38: 4433-40.

Michelson AM, Monny C. (1966) Polynucleotide analogues. IX. Polyxanthylic acid. Biochim Biophys Acta.; 129: 460-74.
Mizuno H, Fujiwara T, Tomita K. (1969) The crystal and molecular structure of the sodium salt of xanthine. Bull Chem Soc Jpn.; 42: 3099-105.

Mizuno K, Kato M, Irino F, Yoneyama N, Fujimura T, Ashihara H. (2003) The first commited step reaction of caffeine biosynthesis: 7-methylxanthosine synthase is closely homologous to caffeine synthases in coffee (Coffea arabica L). FEBS Lett.; 547: $56-60$.

Muller CE, Shi D, Manning M Jr, Daly JW. $(1993)$ Synthesis of paraxanthine analogs (1,7-disubstituted xanthines) and other xanthines unsubstituted at the 3-position: structure-activity relationships as adenosine receptors. J Med Chem.; 36: 3341-9.

Nakano T, Terato H, Asagoshi K, Masaoka A, Mukuta M, Ohyama Y, Suzuki T, Makino K, Ide H. (2003) DNA-protein cross-link formation mediated by oxanine. A novel genotoxic mechanism of nitric oxide induced DNA damage. J Biol Chem.; 278: 25264-72.

Neer EJ. (1995) Heterotrimeric G proteins: organizers of transmembrane signals. Cell.; 80: $249-57$.

Negishi O, Ozawa T, Imagawa H. (1985) Methylation of xanthosine by tea-leaf extracts and caffeine biosynthesis. Agric Biol Chem.; 49: 887-90.

Nemeti B, Csanaky I, Gregus Z. (2003) Arsenate reduction in human erythrocytes and rats - testing the role of purine nucleoside phosphorylase. Toxicol Sci.; 74: 22-31.

Nguyen T, Brunson S, Crespi CL, Penman DW, Tannenbaum SR. (1992) DNA damage and mutation in human cells exposed to nitric oxide in vitro. Proc Natl Acad Sci USA.; 89: 3030-4.

Niedzwiecka A, Marcotrigiano J, Stepinski J, Jankowska-Anyszka M, Wislouch-Cieszynska A, Dadlez M, Gingras A-C, Mak P, Darzynkiewicz E, Sonnenberg N, Burley K, Stolarski R. (2002a) Biophysical studies of eIF4E cap-binding protein: Recognition of mRNA 5 cap structure and synthetic frag- 
ments of eIF4G and 4E-BP1 proteins. $J$ Mol Biol.; 319: 615-35.

Niedzwiecka A, Stepinski J, Darzynkiewicz E, Sonnenberg N, Stolarski R. (2002b) Positive heat capacity change upon specific binding of translation initiation factor eIF4E to mRNA 5 cap. Biochemistry.; 41: 12140-8.

Ogawa M, Herai Y, Koizumi N, Kusano T, Sano H. (2001) 7-Methylxanthine methyltransferase of coffee plants: gene isolation and enzymatic properties. $J$ Biol Chem.; 276: 8213-8.

Ogston AG. (1935) The constitution of the purine nucleosides. Part III. Potentiometric determination of the dissociation constants of methylated xanthines. J Chem Soc.; 1376-9.

Olsen AS, Milman G. (1974) Chinese hamster hypoxanthine-guanine phosphoribosyltransferase. Purification, structural, and catalytic properties. J Biol Chem.; 249: 4030-7.

Ono Y, Ikeda K, Wei MX, Harsh GR 4th, Tamiya T, Chiocca EA. (1997) Regression of experimental brain tumours with 6-thioxanthine and Escherichia coli gpt gene therapy. Hum Gene Ther:; 8: 2043-55.

Pankiewicz KW. (2001) Inhibitors of inosine monophosphate dehydrogenase as potential chemotherapeutic agents. Expert Opin Ther Patents.; 11: 1161-70.

Petersen C, Moller LB. (2001) The RihA, RihB, and RihC ribonucleoside hydrolases of Escherichia coli. J Biol Chem.; 276: 884-94.

Pfefferkorn ER, Bzik DJ, Honsinger CP. (2001) Toxoplasma gondii: mechanism of the parasitostatic action of 6-thioxanthine. Exp Parasitol.; 99: 235-43.

Pfleiderer W. (1961) Zur Methylierung des 9-Methyl-xanthins. Ann Chem.; 647: 161-6.

Pfleiderer W, Nübel G. (1961) Zur Struktur des Xanthins und Seiner N-Methyl-xanthin-derivate. Ann Chem.; 647: 155-60.

Piccirilli JA, Krauch T, Moroney SE, Benner SA. (1990) Enzymatic incorporation of a new base pair into DNA and RNA extends the genetic alphabet. Nature.; 343: 33-7.
Pitera JW, Munagala NR, Wang CC, Kollman PA. (1999) Understanding substrate specificity in human and parasite phosphoribosyltransferases through calculation and experiment. Biochemistry.; 38: 10298-306.

Poznanski J, Kierdaszuk B, Shugar D. (2003) Structural properties of the neutral and monoanionic forms of xanthosine, highly relevant to their substrate properties with various enzyme systems. Nucleosides Nucleotides Nucleic Acids.; 22: 249-63.

Pugmire MJ, Ealick SE. (2002) Structural analyses reveal two distinct families of nucleoside phosphorylases. Biochem J.; 361: 1-25.

Radabaugh TR, Sampayo-Reyes A, Zakharyan RA, Aposhian HV. (2002) Arsenate reductase II. Purine nucleoside phosphorylase in the presence of dihydrolipoic acid is a route for reduction of arsenate to arsenite in mammalian systems. Chem Res Toxicol.; 15: 692-8.

Rastelli G, Costantino L, Albasini A. (1997) A model of the interaction of substrates and inhibitors with xanthine oxidase. $J$ Am Chem Soc.; 119: 3007-16.

Remin M, Darzynkiewicz E, Dworak A, Shugar D. (1976) Proton magnetic resonance studies of the effects of sugar hydroxyl dissociation on nucleoside conformation. Arabinosyl nucleosides with an intramolecular hydrogen bond between the pentose $\mathrm{O}\left(5^{\prime}\right)$ and $\mathrm{O}\left(2^{\prime}\right) . \mathrm{J}$ Am Chem Soc.; 98: 367-76.

Roberts MF, Waller GR. (1979) N-Methyltransferases and 7-methyl- $\mathrm{N}^{9}$-nucleoside hydrolase activity in Coffea arabica and the biosynthesis of caffeine. Phytochemistry.; 18: 451-5.

Rogstad KN, Jang YH, Sowers LC, Goddard WA III. (2003) First principles calculations of the $\mathrm{p} K_{\mathrm{a}}$ values and tautomers of isoguanine and xanthine. Chem Res Toxicol.; 16: $1455-62$.

Rosen BP. (2002) Biochemistry of arsenic detoxification. FEBS Lett.; 529: 86-92.

Rousseau E, LaDine J, Liu Q-Y, Meissner G. (1988) Activation of the $\mathrm{Ca}^{2+}$ release channel 
of skeletal muscle sarcoplasmic reticulum by caffeine and related compounds. Arch Biochem Biophys.; 267: 75-86.

Roy KB, Miles HT. (1983) Tautomerism and ionization of xanthosine. Nucleosides Nucleotides.; 2: 231-42.

Roy KB, Frazier J, Miles HT. (1979) Polyxanthylic acid: Structures of the ordered forms. Biopolymers.; 18: 3077-87.

Roy KB, Frazier J, Miles HT. (1983) Interaction of poly(X) with poly(U): alkali metal ion specificity suggests a four-stranded helix. Biopolymers.; 22: 2021-34.

Sau AK, Mondal MS, Mitra S. (2000) Effect of $\mathrm{pH}$ and temperature on the reaction of milk xanthine oxidase with 1-methylxanthine. $J$ Chem Soc Dalton Trans.; 3688-92.

Schouten KA, Weiss B. (1999) Endonuclease V protects Escherichia coli against specific mutations caused by nitrous acid. Mutation Res.; 435: 245-54.

Schulthess B, Morath P, Baumann TW. (1996) Caffeine biosynthesis starts with the metabolically channelled formation of 7-methyl-XMP - a new hypothesis. Phytochemistry.; 41: 169-75.

Seeger C, Poulsen C, Dandanell G. (1995) Identification and characterization of genes $(x a p A, x a p B$ and $x a p R)$ involved in xanthosine catabolism in Escherichia coli. $J$ Bacteriol.; 177: 5506-16.

Seela F, Driler H, Liman U. (1985) 7-Deaza-isotere von 2 -Desoxyxanthosin und 2-Desoxyspongosin - Syntese via Glycosylierung von 2,4-Dichlor-7H-pyrrolo[2,3-d]pyrimidin. Liebigs Ann Chem.; 312-20.

Sekiguchi M, Tsuzuki, T. (2002) Oxidative nucleotide damage: consequences and prevention. Oncogene.; 21: 8895-904.

Shamim MT, Ukena D, Padgett WL, Daly JW. (1989) Effects of 8-phenyl and 8-cycloalkyl substituents on the activity of mono-, di- and trisubstituted alkylxanthines with substitutions at the 1-, 3-, and 7-positions. $J \mathrm{Med}$ Chem.; 32: 1231-7.
Shi W, Li CM, Tyler PC, Furneaux RH, Cahill SM, Girvin ME, Grubmeyer C, Schramm VL, Almo SC. (1999a) The $2.0 \AA$ structure of malarial purine phosphoribosyltransferase in complex with a transition-state analog inhibitor. Biochemistry.; 38: 9872-80.

Shi W, Li CM, Tyler PC, Furneaux RH, Grubmeyer C, Schramm VL, Almo SC. (1999b) The $2.0 \AA$ structure of human hypoxanthine-guanine phosphoribosyltransferase in complex with a transition-state analog inhibitor. Nat Struct Biol.; 6: $588-93$.

Shugar D, Psoda A. (1990) Numerical data and functional relationships in science and technology. In Biophysics of Nucleic Acids, Landoldt-Bornstein New Series VII/Id. Saenger W. ed, pp 308-48. Springer-Verlag, Berlin.

Somoza JR, Chin MS, Focia PJ, Wang CC, Fletterick RJ. (1996) Crystal structure of the hypoxanthine-guanine-xanthine phosphoribosyltransferase from the protozoan parasite Tritrichomonas foetus. Biochemistry.; 35: 7032-40.

Stoychev G, Kierdaszuk B, Shugar D. (2002) Xanthosine and xanthine: Substrate properties with purine nucleoside phosphorylases, and relevance to other enzyme systems. Eur J Biochem.; 269: 4048-57.

Subbayya INS, Sukumaran S, Shivashankar K, Balaram H. (2000) Unusual substrate specificity of a chimeric hypoxanthine-guanine phosphoribosyltransferase containing segments from the Plasmodium falciparum and human enzymes. Biochem Biophys Res Commun.; 272: 596-602.

Suzuki T, Ide H, Yamada M, Endo N, Kanaori K, Tajima K, Morii T, Makino K. (2000) Formation of 2 -deoxyoxanosine from 2 -deoxyguanosine and nitrous acid: mechanism and intermediates. Nucleic Acids Res.; 28: $544-51$.

Suzuki T, Yoshida M, Yamada M, Ide H, Kobayashi M, Kanaori K, Tajima K, Makino K. (1998) Misincorporation of 2 -deoxyoxanosine-5 -triphosphate by DNA 
polymerases and its implication for mutagenesis. Biochemistry.; 37: 11592-98.

Suzuki T, Matsumura Y, Ide H, Kanaori K, Tajima K, Makino K. (1997) Deglycosylation susceptibility and base-pairing stability of 2 '-deoxyoxanosine in oligodeoxynucleotide. Biochemistry.; 36: 8013-9.

Swierkowski M, Shugar D. (1969) A new thymine base analogue, 5-ethyluracil: 5-ethyluridine-5'-pyrophosphate and poly-5-ethyluridylic acid. Acta Biochim Polon.; 16: $263-77$.

Swierkowski M, Szer W, Shugar D. (1965) Some properties of poly-ribothymidylic acid, co-polymers of uridylic and ribothymidylic acids, and their 1:1 complexes with polyadenylic acid. Biochem Z.; 342: 429-36.

Szer W, Shugar D. (1963) Preparation of poly-5-fluorouridylic acid and the properties of halogenated poly-uridylic acids and their complexes with poly-adenylic acid. Acta Biochim Polon.; 10: 219-31.

Terato H, Masaoka A, Asagoshi K, Honsho A, Ohyama Y, Suzuki T, Yamada M, Makino K, Yamamoto K, Ide H. (2002) Novel repair activities of AlkA (3-methyladenine DNA glycosylase II) and endonuclease VIII for xanthine and oxanine, guanine lesions induced by nitric oxide and nitrous acid. $\mathrm{Nu}$ cleic Acids Res.; 30: 4975-84.

Torrence PF, De Clercq E, Witkop B. (1977) The interaction of polyxanthylic acid with polyadenylic acid. Biochim Biophys Acta.; 475: $1-6$.

Twanmoh L-M, Wood HB Jr, Driscoll JS. (1973) NMR spectral characteristics of N-H protons in purine derivatives. $J$ Heterocycl Chem.; 10: $187-90$.

Uefuji H, Ogita S, Yamaguchi Y, Koizumi N, Sano H. (2003) Molecular cloning and functional characterization of three distinct $\mathrm{N}$-methyltransferases involved in the caffeine biosynthetic pathway in coffee plants. Plant Physiol.; 132: 372-80.

Versees W, Steyaert J. (2003) Catalysis by nucleoside hydrolases. Curr Opin Struct Biol.; 13: 731-8. von der Saal W, Crysler CS, Villafranca JJ. (1985) Positional isotope exchange and kinetic experiments with Escherichia coli guanosine-5'-monophosphate synthetase. Biochemistry.; 25: 5343-50.

Vongchampa V, Dong M, Gingipalli L, Dedon P. (2003) Stability of 2 -deoxyxanthosine in DNA. Nucleic Acids Res.; 31: 1045-51.

Vos S, de Jersey J, Martin JL. (1997) Crystal structure of Escherichia coli xanthine phosphoribosyltransferase. Biochemistry.; 36: 4125-34.

Vos S, Parry RJ, Burns MR, de Jersey J, Martin JL. (1998) Structures of free and complexed forms of Escherichia coli xanthine-guanine phosphoribosyltransferase. J Mol Biol.; 282: 875-89.

Waalkes MP, Liu J. (2002) Purine nucleoside phosphorylase: A fortuitous cytosolic arsenate reductase? Toxicol Sci.; 70: 1-3.

Wang CC. (1984) Parasite enzymes as potential targets for antiparasitic chemotherapy. $J$ Med Chem.; 27: 1-9.

Wang JK, Morris AJ. (1974) The distribution of nucleoside triphosphate pyrophosphohydrolase in the tissue of the rabbit. Arch Biochem Biophys.; 161: 118-24.

Wierzchowski J, Wielgus-Kutrowska B, Shugar D. (1996) Fluorescence emission properties of 8-azapurines and their nucleosides, and application to the kinetics of the reverse synthetic reaction of purine nucleoside phosphorylase. Biochim Biophys Acta.; 1290: 9-17.

Wilson DM III, Sofinowski TM, McNeill DR. (2003) Repair mechanisms for oxidative DNA damage. Front Biosci.; 8: 963-81.

Wuenschell GE, O'Connor TR, Termini J. (2003) Stability, miscoding potential, and repair of 2 -deoxyxanthosine in DNA: Implications for nitric oxide-induced mutagenesis. Biochemistry.; 42: 3608-16.

Xu Y, Grubmeyer C. (1998) Catalysis in hypoxanthine-guanine phosphoribosyltransferase: Asp137 acts as a general acid/base. Biochemistry.; 37: 4114-24. 
Yamada Y, Goto H, Yoshino M, Ogasawara N. (1990) IMP dehydrogenase and action of antimetabolites in human cultured blast cells. Biochim Biophys Acta.; 1051: 209-14.

Yan L, Muller CE. (2004) Preparation, properties, reactions, and adenosine receptor affinities of sulfophenylxanthine nitrophenyl esters: towards the development of sulfonic acid prodrugs with peroral bioavailability. $J$ Med Chem.; 47: 1031-43.

Yanachkov I, Pan JY, Wessling-Resnick M, Wright GE. (1997) Synthesis and effect of nonhydrolyzable xanthine triphosphate derivatives on prenylation of Rab5D136N. Mol Pharmacol.; 51: 47-51.

Yu B, Slepak Z, Simon M. (1997) Characterization of a $\mathrm{G} \alpha$ mutant that binds xanthine nucleotides. J Biol Chem.; 272: 18015-9.

Yu B, Gu L, Simon M. (2000) Inhibition of subsets of $\mathrm{G}$ protein-coupled receptors by empty mutants of $G$ protein alpha subunits in $G_{0}$, $\mathrm{G}_{11}$ and $\mathrm{G}_{16}$. J Biol Chem.; 275: 71-6. 